\title{
Post-Retrofit Residential Assessments
}

Technical Contributors:

R Lancaster

S Widder

L Lutzenhiser S Chandra

M Moezzi

Project Manager:

M Baechler

April 2012

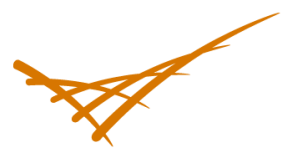

Pacific Northwest

NATIONAL LABORATORY

Proudly Operated by Battelle Since 1965 


\title{
DISCLAIMER
}

This report was prepared as an account of work sponsored by an agency of the United States Government. Neither the United States Government nor any agency thereof, nor Battelle Memorial Institute, nor any of their employees, makes any warranty, express or implied, or assumes any legal liability or responsibility for the accuracy, completeness, or usefulness of any information, apparatus, product, or process disclosed, or represents that its use would not infringe privately owned rights. Reference herein to any specific commercial product, process, or service by trade name, trademark, manufacturer, or otherwise does not necessarily constitute or imply its endorsement, recommendation, or favoring by the United States Government or any agency thereof, or Battelle Memorial Institute. The views and opinions of authors expressed herein do not necessarily state or reflect those of the United States Government or any agency thereof.

\author{
PACIFIC NORTHWEST NATIONAL LABORATORY \\ operated by \\ BATTELLE \\ for the \\ UNITED STATES DEPARTMENT OF ENERGY \\ under Contract DE-AC05-76RL01830
}

Printed in the United States of America

$$
\begin{aligned}
& \text { Available to DOE and DOE contractors from the } \\
& \text { Office of Scientific and Technical Information, } \\
& \text { P.O. Box } 62 \text {, Oak Ridge, TN } 37831-0062 \text {; } \\
& \text { ph: }(865) 576-8401 \\
& \text { fax: (865) 576-5728 } \\
& \text { email: reports@adonis.osti.gov }
\end{aligned}
$$

Available to the public from the National Technical Information Service

5301 Shawnee Rd., Alexandria, VA 22312 ph: (800) 553-NTIS (6847)

email: orders@ntis.gov $<$ http://www.ntis.gov/about/form.aspx $>$

Online ordering: http://www.ntis.gov 
PNNL-21362

\section{Post-Retrofit Residential Assessments}

Technical Contributors:

R Lancaster ${ }^{1}$

S Widder ${ }^{2}$

L Lutzenhiser ${ }^{1}$

S Chandra $^{2}$

M Moezzi ${ }^{1}$

Project Manger:

M Baechler ${ }^{2}$

April 2012

Prepared for

the U.S. Department of Energy

under Contract DE-AC05-76RL01830

Pacific Northwest National Laboratory

Richland, Washington 99352

\footnotetext{
${ }^{1}$ Portland State University, Center for Urban Studies, Toulan School of Urban Studies and Planning; Portland, Oregon

${ }^{2}$ Pacific Northwest National Laboratory; Richland, Washington
} 



\section{Summary}

This study examined a range of factors influencing energy consumption in households that had participated in residential energy-efficiency upgrades. The study was funded under a subcontract with the U.S. Department of Energy's Pacific Northwest National Laboratory and was conducted by faculty and staff of Portland State University Center for Urban Studies and Department of Economics. This work was made possible through the assistance and support of the Energy Trust of Oregon (ETO), whose residential energy-efficiency programs provided the population from which the sample cases were drawn. All households in the study had participated in the ETO Home Performance with Energy Star (HPwES) program. A number of these had concurrently pursued measures through other ETO programs.

Post-retrofit energy outcomes are rarely investigated on a house-by-house basis. Rather, aggregate changes are ordinarily the focus of program impact evaluations, with deviation from aggregate expectations chalked up to measurement error, the vagaries of weather, and idiosyncrasies of occupants. However, understanding how homes perform post-retrofit on an individual basis can give important insights to increase energy savings at the participant and the programmatic level. Taking a more disaggregated approach, this study analyzed energy consumption data from before and after the retrofit activity and made comparisons with engineering estimates for the upgrades, to identify households that performed differently from what may have been expected based on the estimates. A statistical analysis using hierarchal linear models, which accounted for weather variations, was performed looking separately at gas and electrical use during the periods before and after upgrades took place. A more straightforward comparison of billing data for 12-month periods before and after the intervention was also performed, yielding the majority of the cases examined. The latter approach allowed total energy use and costs to be assessed but did not account for weather variation.

From this statistical analysis, 18 study participants were selected and interviewed. The participants completed an in-home interview covering a range of topics, including changes in occupancy and additional changes to the homes that may have affected energy use. The goal of the interviews was to identify factors that may have contributed to unusual energy performance. These factors were identified by their frequency of occurrence in outperforming or underperforming homes, or simply by identifying factors that had the largest impact on overall savings. The motivations and levels of satisfaction with the outcomes of the upgrades were covered in detail, and behaviors pertaining to thermal control, lighting, water, and appliance use were extensively discussed.

Most of the cases studied achieved substantial energy savings, although it was more common for the projected savings to be greater than the demonstrated savings. Two factors that played a very large role in savings variation were 1) changes in occupancy and 2) fenestration improvements outside of the incentive programs. Motivation for pursuing the upgrades (e.g., environmental sustainability vs. comfort or cost savings) did not seem to play any role in achieving savings. Participants generally were more concerned with maintaining aesthetics through lighting than comfort through heating or cooling. They also seemed more likely to turn the lights off when leaving a room than to turn the heat off when leaving the home. 



\section{Acknowledgments}

This study was conducted by researchers at Portland State University (PSU) Center for Urban Studies for the Pacific Northwest National Laboratory (PNNL). The work was funded by the U.S. Department of Energy Building America Program with funds derived from the American Recovery and Reinvestment Act of 2009. PNNL and PSU thank the DOE for its support.

For this work, the PNNL contributors provided technical oversight and project management. The PNNL researchers are grateful for the hard work, dedication, and flexibility of the PSU team. Specifically, Ross Lancaster served as the primary researcher, conducted surveys and performed the analysis. Dr. Loren Lutzenhiser served as principal investigator and project manager for the PSU research team, contributing significantly on the administrative coordination and report writing. The PNNL team is also grateful for the contributions of Mithra Moezzi, who managed the data and conducted the analysis, working in collaboration with Mr. Lancaster.

The project team is indebted to Subrato Chandra for his exceptional leadership and insight. Subrato managed this task at PNNL until his unexpected death in January 2012. We also acknowledge Heather Dillon and Rosemarie Bartlett, for their peer reviews, and Susan Ennor, for her editorial expertise. The work was made possible by the assistance and support of the Energy Trust of Oregon (ETO), whose residential energy-efficiency programs provided the population from which the sample cases were drawn. ETO not only made its data available, but also helped the project team to overcome restrictions to accessing the data.

Finally, PNNL and PSU wish to thank the homeowners who participated in this study. Their willingness to take time out of their schedule to revisit questions regarding energy consumption in their homes made the study possible. 



\section{Acronyms and Abbreviations}

$\begin{array}{ll}\text { CDD } & \text { Cooling Degree Day } \\ \text { CFL } & \text { compact fluorescent light } \\ \text { DHW } & \text { domestic hot water } \\ \text { ETO } & \text { Energy Trust of Oregon } \\ \mathrm{ft}^{2} & \text { square foot (feet) } \\ \mathrm{HDD} & \text { Heating Degree Day } \\ \mathrm{HES} & \text { Home Energy Solutions } \\ \mathrm{HPwES} & \text { Home Performance with Energy Star } \\ \mathrm{kBtu} & \text { thousand British thermal units } \\ \mathrm{kWh} & \text { kilowatt-hour(s) } \\ \text { PNNL } & \text { Pacific Northwest National Laboratory } \\ \text { PRISM } & \text { Princeton Score Keeping Method } \\ \text { PSU } & \text { Portland State University }\end{array}$





\section{Contents}

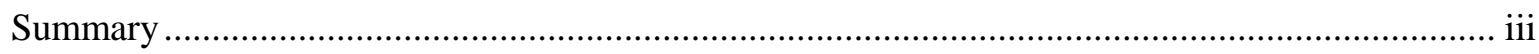

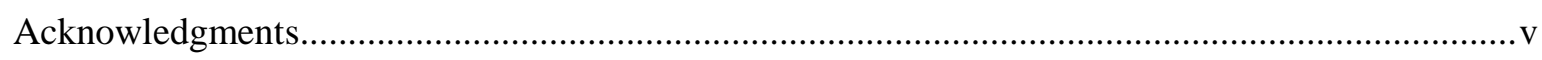

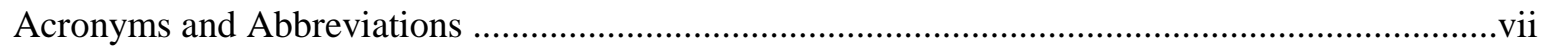

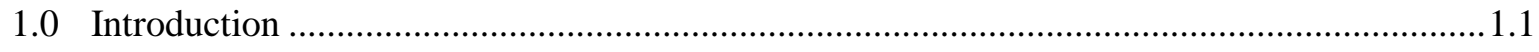

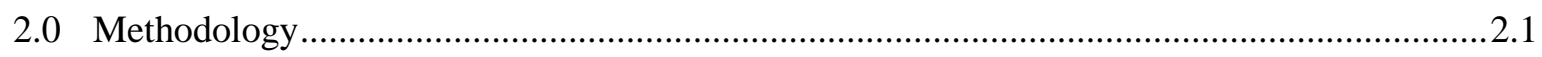

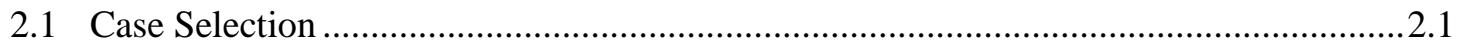

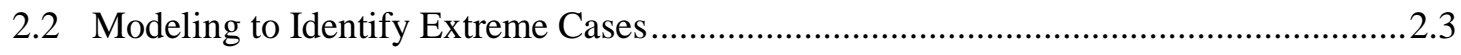

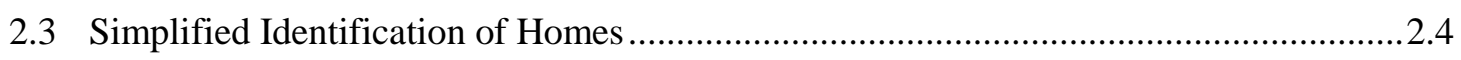

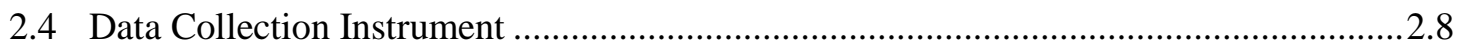

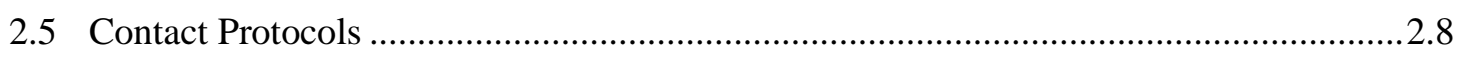

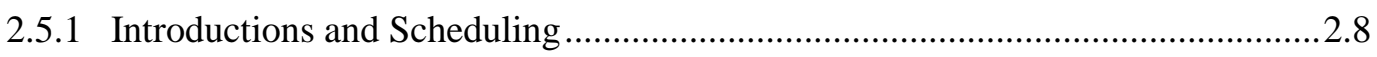

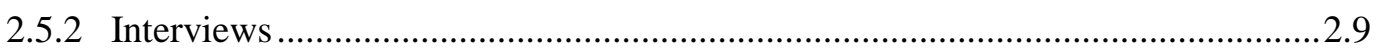

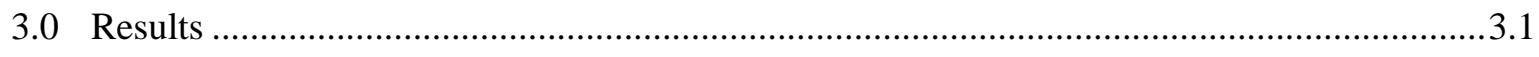

3.1 Savings Potentials versus Realized Savings.............................................................. 3.1

3.1.1 Savings > 20\% Above Predictions (dark blue circles) ........................................... 3.6

3.1.2 Within 20\% Plus or Minus of Predictions (red circles) ........................................ 3.8

3.1.3 Savings $>20 \%$ Below Predictions (green circles) .............................................. 3.8

3.1.4 Increased Energy Use (purple circles)............................................................. 3.9

3.1.5 Cases Involving Erroneous Pre-Retrofit Utility Bill Data (not circled) ................3.9

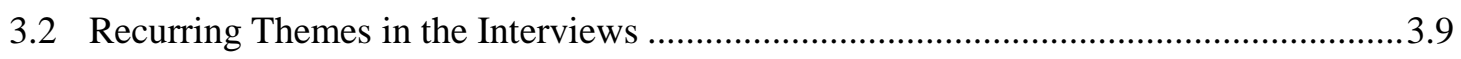

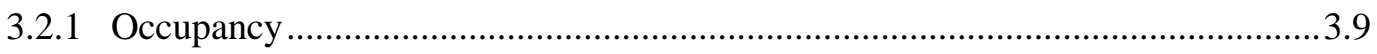

3.2.2 Thermal Control ….............................................................................. 3.10

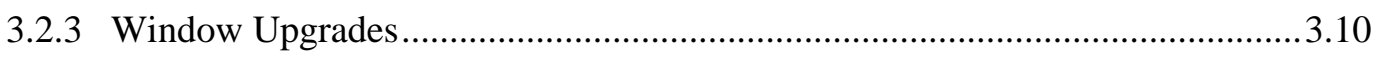

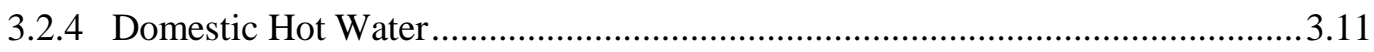

3.2.5 Habits and Rational Calculation ................................................................. 3.11

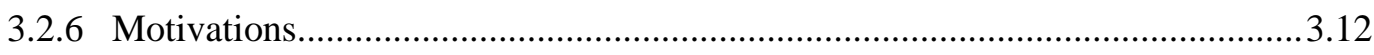

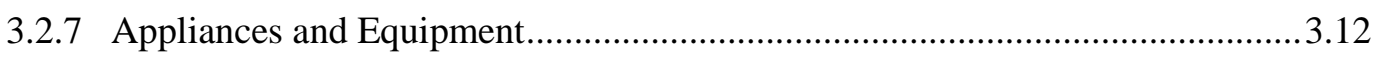

3.3 Characterizing "Savers" and "Spenders" ................................................................13

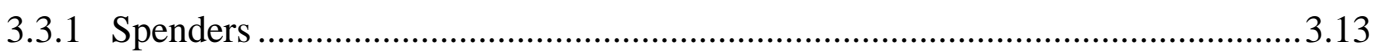

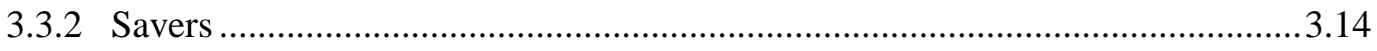

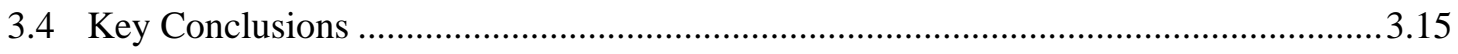

4.0 Lessons Learned and Future Research ........................................................................ 4.1

4.1 Challenges in Accessing Program Data ................................................................... 4.1

4.2 Discovering Data Limitations ............................................................................... 4.1

4.3 Homeowner Reticence Relative to Being Interviewed .............................................4.1

4.4 Losing Most of the Cases with Low Savings ............................................................... 4.2 
4.5 Database Problems Discovered During the Interview Stage ......................................... 4.2

4.6 Uncooperative Weather for High-Quality Thermal Imaging ........................................ 4.2

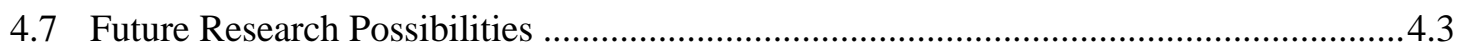

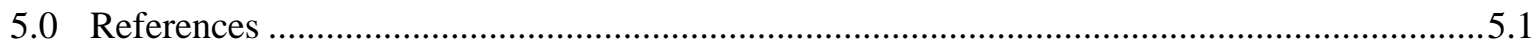

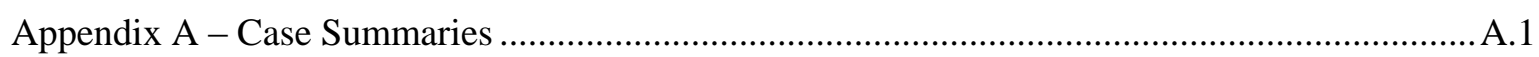

Appendix B - Energy Trust Introductory Letter........................................................................ B.1

Appendix C - Gift Card Documents ................................................................................. 1

\section{Figures}

Figure 1.1. Distribution of Household Energy Intensity in ETO Program Population ..................1.1

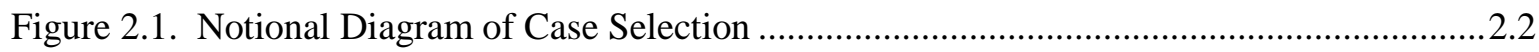

Figure 2.2. Engineering Estimates of Participant Energy Reductions .........................................2.2

Figure 2.3. Projected Savings as Percent of Household Energy Expense.....................................2.5

Figure 2.4. Twelve-Month Household Energy Cost Change ....................................................... 2.6

Figure 2.5. Change in Household Energy Cost Intensity, Post-Retrofit ....................................... 2.7

Figure 2.6. Comparing Heating Degree Day Patterns..................................................................2.7

Figure 3.1. Comparison of Installed Measures, Interview Sample, and Program Population .........3.2

Figure 3.2. Estimated Annual Dollar Cost Reductions for Sample Households...............................3.3

Figure 3.3. Actual Household Cost Differences (\$) Pre- and Post-Upgrade .................................3.3

Figure 3.4. Household Energy Cost Savings Projections and Results ..............................................

Figure 3.5. Household Energy Cost Savings Projections and Results by Fuel Source ....................3.4

Figure 3.6. Household Energy Intensity - Interviewed Sample .................................................. 3.5

Figure 3.7. Household Energy Intensity by Utility - Interviewed Sample ..................................... 3.6

Figure 3.8. Estimated and Realized Change in Energy Cost by Fuel Source ................................. 3.6 


\subsection{Introduction}

Faculty and staff of Portland State University (PSU) Center for Urban Studies and Department of Economics conducted a study to examine a range of factors influencing energy consumption in households that had participated in residential energy-efficiency upgrades. Funded under a subcontract with the U.S. Department of Energy's Pacific Northwest National Laboratory, the work was made possible by the assistance and support of the Energy Trust of Oregon (ETO), whose residential energyefficiency programs provided the population from which the sample cases were drawn. All households in the study had participated in the ETO Home Performance with Energy Star (HPwES) program, and a number of them had concurrently pursued energy-efficiency measures through other ETO programs.

The project identified households within the three-county Portland metropolitan area that saved less or more than predicted and investigated a range of possible factors influencing the changes in energy consumption resulting from a major home energy retrofit program conducted by the ETO. The Trust operated the Home Performance with ENERGYSTAR initiative during the period from 2008 to the present. A total of 268 households received detailed onsite energy audits with diagnostic testing and building energy simulation modeling. Nearly every household (97\%) also installed a variety of retrofit measures, for which ETO program rebates were provided. These retrofits ranged from compact fluorescent lights (CFLs) to expensive furnace or window replacements, and often included multiple measures. In addition, data were collected about participants' energy consumption before and after the retrofit interventions, and aggregate program energy savings were estimated and program costeffectiveness calculated (ETO 2011). As shown in Figure 1.1, there was a marked decrease in the energy intensity of households that participated in the ETO program. Participating households, for which consumption data were available, exhibited an average decrease in household energy intensity of $12 \%$, from $49.5 \mathrm{kBtu} / \mathrm{ft}^{2}$ to $43.4 \mathrm{kBtu} / \mathrm{ft}^{2}$. The program database also provided sufficient information to support additional work focused on disaggregate (i.e., household-specific) analysis of consumption and savingsthe focus of the research reported in the subsequent sections of this report.

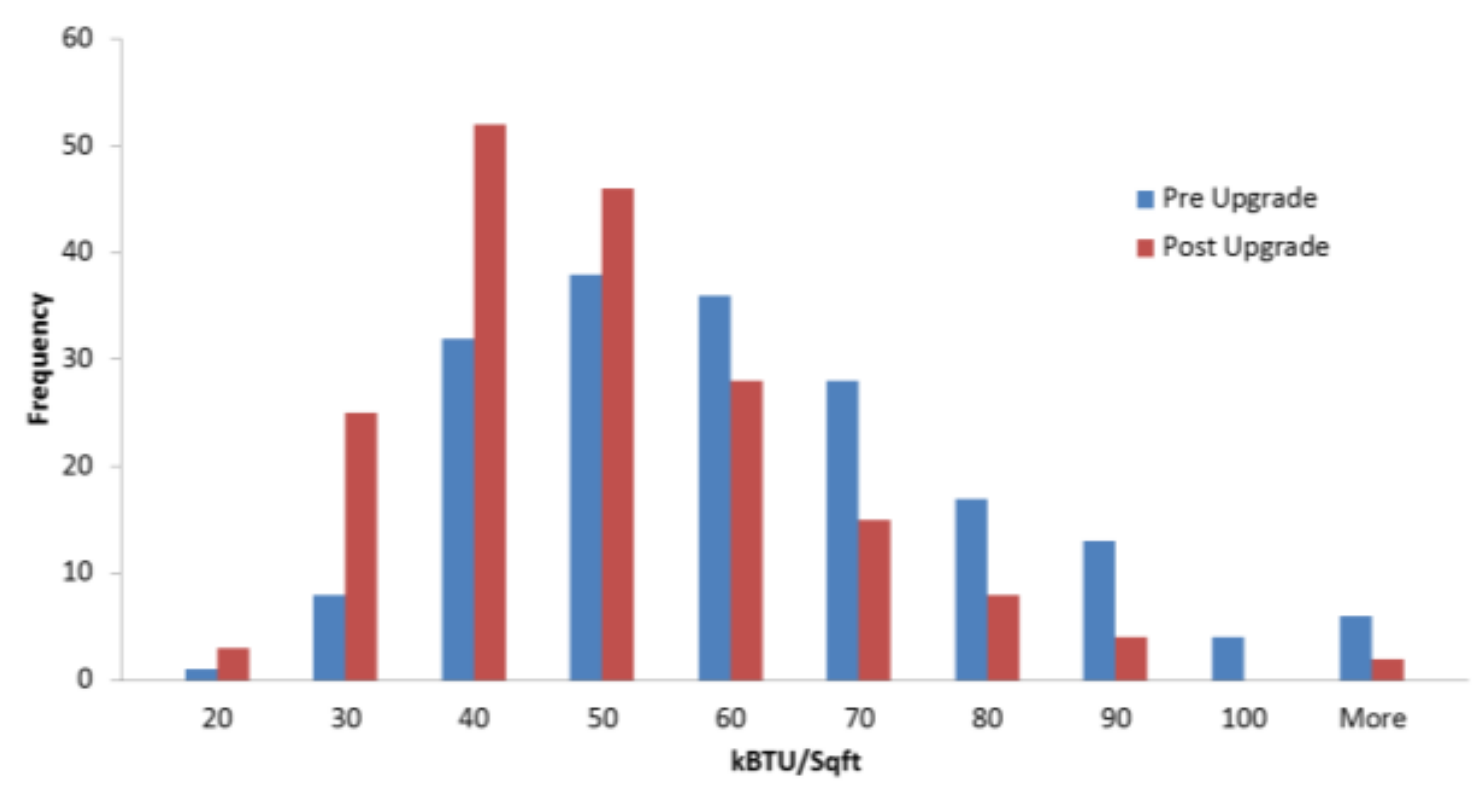

Figure 1.1. Distribution of Household Energy Intensity in ETO Program Population 
The ensuing sections of this report describe the study methodology, results, lessons learned, and their potential application to future research. Appendices contain supplementary information about the case studies and requests and inducements for homeowner participation in the case studies.

This study specifically looked at the behavior patterns of homeowners with regard to energy in the wake of the energy-efficiency changes they had made to their homes. The team endeavored to characterize consumption behavior and identify what, if any, changes to this behavior accompanied retrofit activity. As part of this, the homeowners' perceptions of the effectiveness of the appliance and envelope improvements on energy use were examined as well perceptions of the importance of homeowner behavior. Through this research, common traits have been identified that might be addressed in future programs to better achieve intended results. 


\subsection{Methodology}

The research used the ETO database information that provided participating home characteristics, energy consumption data, and conservation measures implemented. Because there was a wide range of household-level savings combined in the aggregate, the goal was to identify a subset of cases "at the extremes" that either under-performed in terms of energy savings (evidenced by savings that were lower than expected from the retrofit measures undertaken) or over-performed (savings exceeded predictions and expectations). Two approaches were used to identify cases warranting investigation. The first used econometric modeling, which attempted to take into account some significant weather differences between the pre- and post-retrofit periods. The second approach compared energy use for 12 months before and 12 months after the retrofit activity, which could take place in a single day or over a period of several months. Energy comparisons were made both in absolute terms and relative to the engineering estimates of savings for the work performed. This method does not account for differences in weather or involve the estimation uncertainties of the econometric approach.

After identifying a subset of houses whose savings were lower than expected, using a combination of the two sampling techniques, the PSU research team contacted the homeowners and attempted to schedule informal interviews to identify possible factors influencing the unexpected performance. Team members also revisited some of the highly achieving homes to distinguish factors contributing to higherthan-expected savings.

The research team also investigated salient factors that may have influenced energy savings in the selected homes. These data included case records, existing audit results, occupancy data (e.g., changes in number of occupants), and building characteristics related to energy performance. Data gathering involved a phone interview and, whenever possible, a site visit to inspect installations and interview the occupants in more detail.

\subsection{Case Selection}

Retrofit cases were selected through a variety of analytical means intended to identify homes with post-retrofit energy performance that may have varied from what had been projected when the energy upgrades were performed. These approaches and the data that were used in the selection are detailed below. Separate criteria were used to identify sets of potential cases, with particular attention paid to cases meeting multiple criteria. A notional diagram of the sets examined is shown in Figure 2.1.

\subsubsection{Billing Data}

The ETO maintains a database of energy consumption data for all customers of participating utilities. The ETO is responsible for acquiring conservation resources for these utilities and tracks data on the implementation of these services. These data are used for the evaluation and verification of savings obtained through its programs. This database of utility customers was used to compare natural gas and electricity before and after the implementation of conservation measures. For this study, electric and gas usage data from the period of January 2007 through March 2011 were used. Due to the confidential nature of this information, the data were accessed through a secure FTP server maintained by the ETO. A contractor to the ETO who partnered with PSU on this project performed all handling and analysis of the data. 


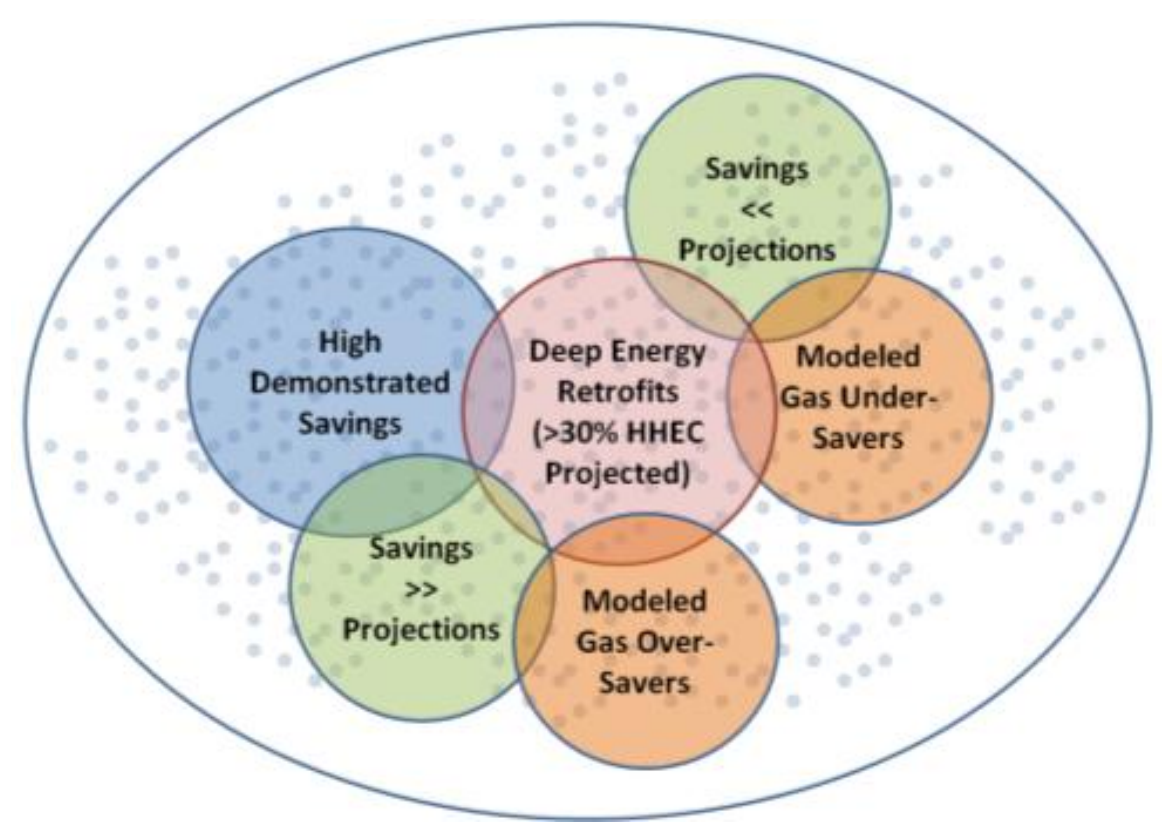

Figure 2.1. Notional Diagram of Case Selection

\subsubsection{Conservation Measure Data}

The ETO also maintains a database of energy conservation measures that receive subsidies/rebates or are otherwise associated with ETO program activities. These measures are grouped together concurrently into projects that are assigned to individual sites and accounts. Several measures may be grouped in a single project. Similarly, several projects may take place at a site or account over a period of years.

The estimated impacts of the projects within the ETO program are shown in Figure 2.2. Tracked with the measures are data relevant to the measure. For instance, an insulation measure will include data on the $\mathrm{R}$-values before and after the measure and sealing measures will have values for exfiltration rates.

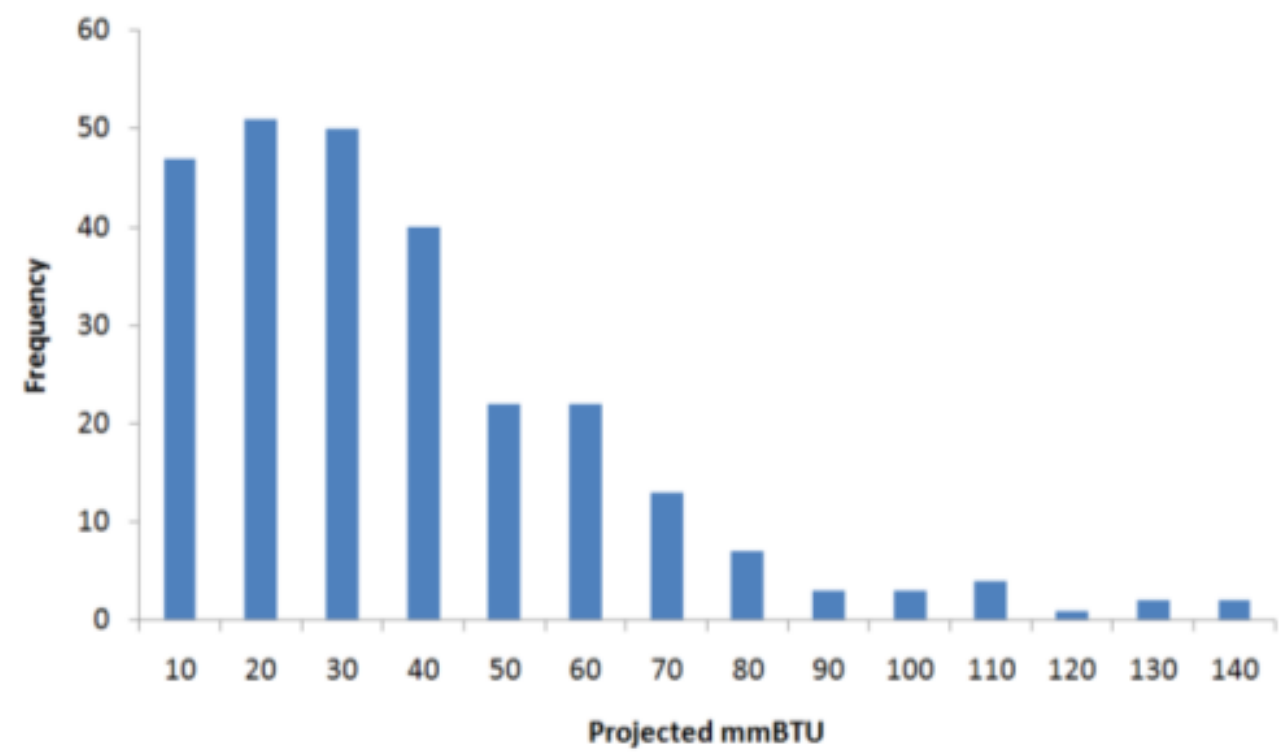

Figure 2.2. Engineering Estimates of Participant Energy Reductions 
While the study focused on measures installed in 2009, the research team also looked at measures performed earlier and later that may have influenced the energy models. The data were accessed through a secure FTP server maintained by the ETO. Because the data contain no identifying or confidential information, they were accessible to both PSU and contractor teams.

\subsubsection{Weather Data}

Daily average temperatures for the period under study were obtained from the National Weather Service Portland Station. Heating Degree Days (HDDs) and Cooling Degree Days (CDDs) — both base $65^{\circ} \mathrm{F}$ - were calculated for each day within the study using Microsoft Excel.

\subsection{Modeling to Identify Extreme Cases}

Using the identified data streams, the research team identified households that saved either considerably more or considerably less than anticipated, based on the available utility bill information. The energy auditor's assessment of both gas and electric savings was compared to econometric models of gas and electricity use to identify homes of interest. Econometric modeling was used to account for weather differences between pre- and post-retrofit periods. The models used to assess savings are a variation of the Princeton Score Keeping Method (PRISM). The models attempt to explain monthly energy use ( $\mathrm{kWh}$ and therms), using HDDs, CDDs, and the square footage of the home as predictor/control variables, and utility billing measures before and after the major renovation as dependent variables.

The electricity and natural-gas models vary slightly. Because it is not practical to estimate a separate model for each household (there are not enough observations), the models were designed to allow key differentiating variables to vary by household while other, more general variables remained constant. In the natural-gas model, households are allowed to have variable responses to HDDs/ $\mathrm{ft}^{2}$, but use attributed to the size of the building, a proxy for hot water use, and the use independent of square footage, were constrained to be the same for all households. This is done to differentiate between weather-dependent and base load gas energy consumption. In the electric model, reactions to CDDs/ $\mathrm{ft}^{2}$ were restricted to be the same for all households. Similarly, the reaction to HDDs $/ \mathrm{ft}^{2}$, separated by heating fuel, was restricted to be the same for all households with the same heating fuel type. The reaction to square footage when the water-heating fuel was electric, a proxy for water-heating demand, was also constrained to be identical for all households with that water-heating fuel. The research team allowed for idiosyncratic daily use, which can be thought of as base load.

All parameters were allowed to differ in the pre- and post-renovation periods. This is an imperfect compromise, but it allowed the research team to roughly identify households that either failed to meet or exceeded savings expectations correcting for 1) fuel changes, 2) weather differences in the pre- and postrenovation periods, 3) differences in the starting and ending times of renovation, and 4) changes in square footage. Once these econometric models were estimated, researchers used the parameter estimates from the pre- and post-renovation models to forecast the annual gas and electricity use for each household, using the actual HDDs and CDDs in each billing period. This forecast was then compared to the engineering estimates of savings. The homes with the largest differences between estimated and realized savings (both positive and negative) were selected for further analysis and interviews. 
This method of comparing econometric model results to savings estimates produced by auditors has strengths and weaknesses. First, due to modeling uncertainties, a large numerical difference in the two forecasts does not mean that there is a "real" (empirically determinable) difference between the two estimates. While the engineering estimates do not come with measurements of uncertainty, the forecasts from the regression-based models do. For some households, estimates of gas and electricity usage in a typical weather year were quite precise, whereas for other estimates had uncertainties as large as $20,000 \mathrm{kWh}$. A second factor influencing the accuracy of this comparison is the accuracy of the engineering estimates. Some of the engineering estimates were clearly off scale with saving estimates larger than historic use. Because the auditors used a well-accepted state-of-the-art model, biases of this magnitude merit further attention. However, the research team was not able to access the model inputs from ETO contractors, so team members were unable to determine the extent to which model architecture/assumptions or modeler error were involved in particular cases of this sort.

Based on the modeling comparisons, the following groups were assembled:

- households with increased natural-gas use from the pre-intervention period to the post-intervention period

- households projected by the ETO to save more than the $50 \%$ of the mean Oregon residential naturalgas consumption that achieved less than $25 \%$ of the projected savings

- households that saved the least gas, relative to their projected savings

- households with increased electric use from the pre-intervention period to the post-intervention period

- households that saved the least electricity, relative to their projected savings

- households that saved the most electricity, relative to their projected savings

- households that saved the most electricity.

Because we have a higher level of confidence in the gas results of this analysis, households with overpredicted or under-predicted gas savings constituted the first cohort of homes contacted for interviews.

\subsection{Simplified Identification of Homes}

Due to the error inherent in the econometric modeling approach, the research team conducted another more simplified comparison to identify any additional homes that may have been missed in the econometric comparison. This simpler analysis was performed by comparing billing data from 12-month periods preceding and following the retrofit activity, without accounting for weather variations. As before, energy use for the 12-month periods preceding and following the upgrade periods were compared, excluding the period in which upgrades were being performed. This utility bill analysis was compared to ETO savings estimates to select additional cases. The following criteria were used to select cases:

- households projected to save more than $30 \%$ of the previous 12-month energy expenditure

- households with a greater than 50\% increase in annual energy costs post retrofit

- households with a greater than $30 \%$ decrease in annual energy costs post retrofit

- households pursuing energy retrofits projected to save greater than $30 \%$ of total energy cost for the preceding 12-month period. 
One of the truly surprising results of performing this analysis was the magnitude of the savings projected by the ETO and its contractors relative to the historic consumption. As seen in Figure 2.3, some of these projections were extremely - and even impossibly - high, in comparison to actual energy bills or usage. A number of households had savings estimates that were in excess of $50 \%$ of actual energy use. Some projections even exceeded the total energy expenditures of the previous 12-month period.

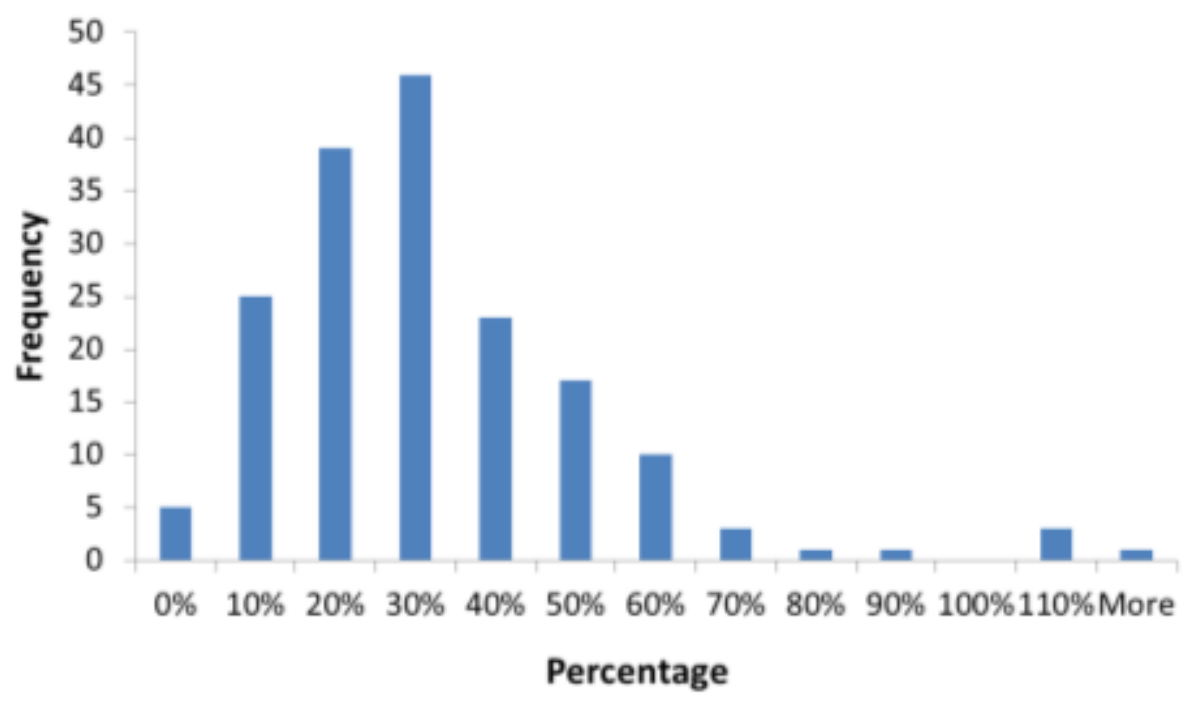

Figure 2.3. Projected Savings as Percent of Household Energy Expense

All of the cases with projected savings in excess of $30 \%$ of prior year energy expense, and that fell within the study's geographic range (the three-county Portland metropolitan area), were contacted. Unfortunately, none of the cases with savings projections exceeding $100 \%$ participated in the study. A number of homes with projected savings in excess of 50\% were investigated. In these instances, there were substantial demonstrated savings, in the $20-30 \%$ range, although the striking projections were not fully realized.

That the ambitious projections were not fully realized is not surprising, although the fact that such estimates are being made and recorded is curious. Existing homes are extremely unlikely to achieve these kinds of savings without extensive and intrusive renovations. In most of these cases the measures were limited to additional insulation, air sealing, and heating hardware, with some instances of window or appliance replacement.

Rather than assuming the projections to be erroneous, it is important instead to look at how they are used and evaluated. From the perspective of supply planning, the objective for the acquisition of conservation resource is not that each individual measure meets the cost objectives set forth, rather that the portfolio of homes performing retrofits as an aggregate achieves the established savings goals. Therefore, conservation measures are ordinarily evaluated as an aggregate, rather than for consistency of performance in individual households. The implied assumption behind this is that some measures will perform better than anticipated and some worse, but all measures and all households combined will achieve the total, aggregated level of savings. Figure 2.4 shows the average utility bill savings for all households for which the research team had data, which illustrates an average $10 \%$ savings due to retrofit measures. 


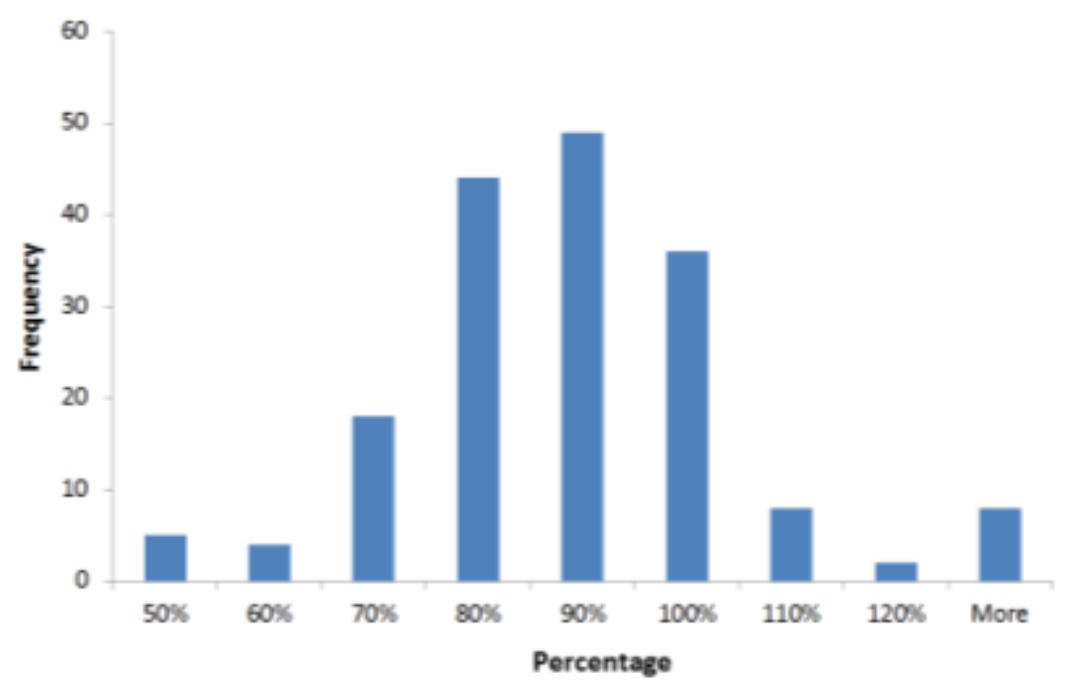

Figure 2.4. Twelve-Month Household Energy Cost Change

A contributing factor to the inconsistencies in the savings projections is the necessity of combining measures from multiple programs. While the focus of the study is the HPwES program, in many cases households participated in multiple programs. To exclude these measures from the analysis would certainly lead to underestimation of savings performance. Including these measures and their projections increases the uncertainty, but provides a more complete picture. ${ }^{1}$

Another way to examine changes in consumption and savings in the ETO program population is to compare differences in total monthly energy costs for a selected time period. Figure 2.4 and Figure 2.5 show that, as might be expected, most participating households experienced a decrease in costs. From Figure 2.5, it is also notable that while the majorities of both the program population and the study sample exhibited cost savings, the sample cases were proportionally more extreme. This is true of both high savings levels and increases in consumption. Because the selection process was intended to identify anomalous cases, this should be considered to be a positive indication.

\footnotetext{
${ }^{1}$ Furthermore, these programs have different means of determining savings, and the methods are not necessarily static. An engineering evaluation of the Home Energy Solutions (HES) program, a predecessor of HPwES, determined that most building envelope measures could not be properly evaluated due to inconsistencies in the data provided. In addition, the report stated: "HES program savings are revised on a continuous basis due to information from program evaluations, field data, and/or in-house planning decisions. (Notably, the continuous nature in updating program estimates made the review less straightforward than originally anticipated. Differing values, as well as measure lists, were provided during the course of the review.)" (Heschong Mahone Group, Inc. 2009). This is indicative of the known limitations in the data set, and also the direction from which the HPwES program is evolving - toward a comprehensive modeling-based approach from an ad hoc collection of estimating tools. At the time of this study, however, this seems to still be a work in progress, and one to which researcher access was limited.
} 


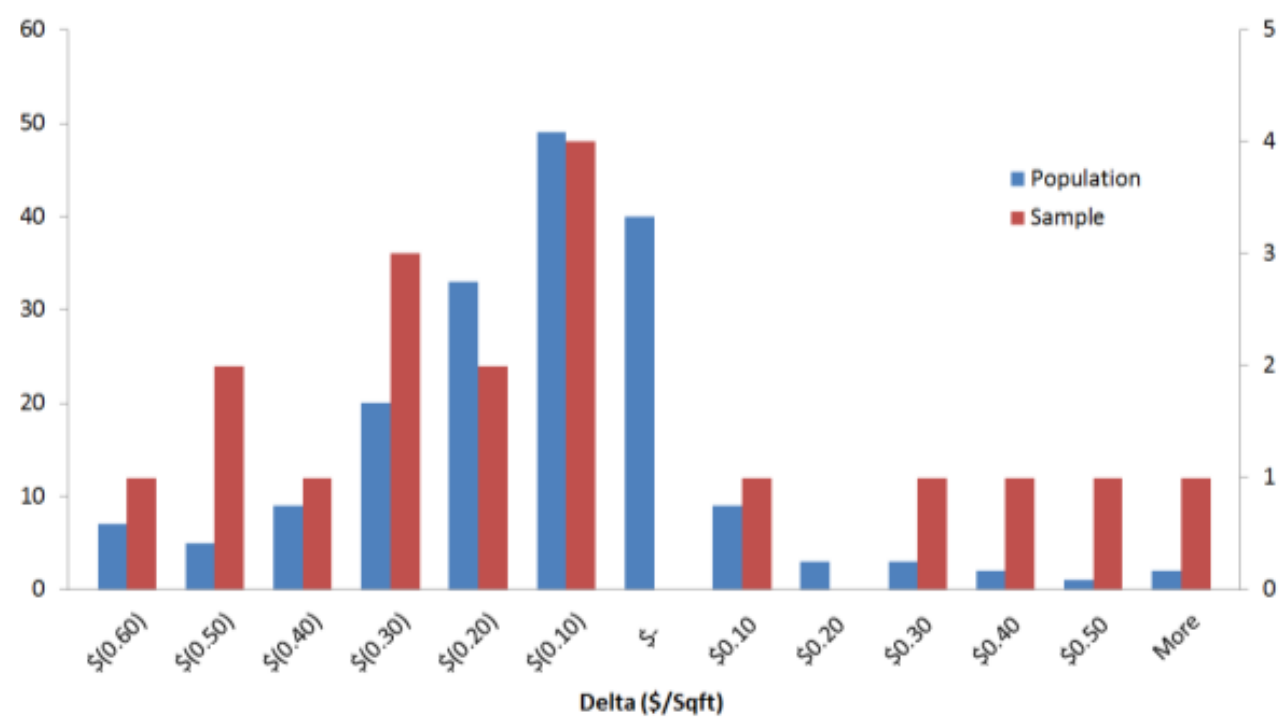

Figure 2.5. Change in Household Energy Cost Intensity, Post-Retrofit

Comparing energy costs for the periods before and after retrofit activity without accounting for weather is imperfect but provides useful insights. However, the econometric analysis produces results that some consider ambiguous, with sometimes-large uncertainties. This is why the research team also attempted to make non-weather-adjusted comparisons. However, to validate the accuracy of a non-weather-adjusted comparison, one needs to understand the absolute difference in weather experienced in the two comparison periods. Weather data for the pre- and post-retrofit periods were examined to determine whether temperature differences could have had a significant effect on energy consumption. However, because households were enrolled and conducted retrofits over several years (and the length of the retrofit activity varied between households), the precise 12-month pre-retrofit and post-retrofit periods were different for virtually every household. This complicated the comparison of pre- and post-retrofit weather periods. Nonetheless, when monthly HDD patterns for a period that roughly coincides with the population pre-retrofit period are compared to the subsequent year (Figure 2.6) the two periods are found to be quite similar. The post-retrofit period was slightly less cold (about 280 HDDs lower on average), which is a $6 \%$ difference. Thus, the research team was fairly confident that non-weather-adjusted comparisons should be descriptive of actual savings achieved due to retrofit activity.

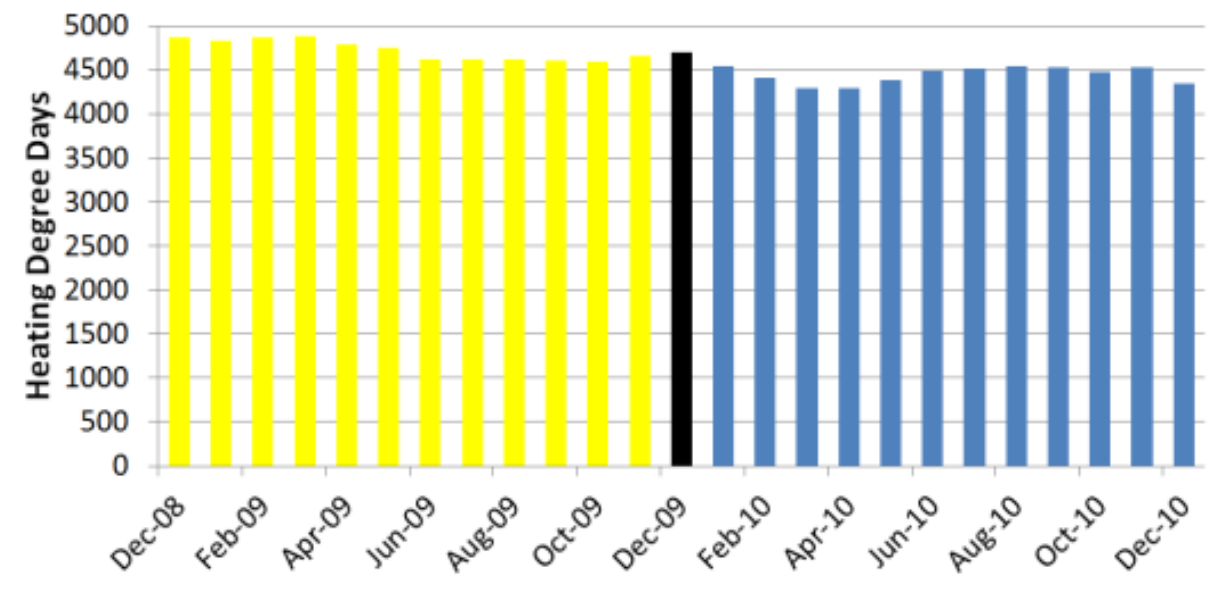

Figure 2.6. Comparing Heating Degree Day Patterns 


\subsection{Data Collection Instrument}

The owners of homes selected for further analysis were interviewed to explore a variety of factors that may influence energy consumption. An interview questionnaire was designed to primarily focus on factual information, but also included some questions that delve more into beliefs and motivations that may have influenced any actions taken. The structure of the interview was intended to lead with "easier" questions that are fact-based and current or recent. This establishes a level of confidence in the respondents that they will be able to answer adequately and builds some rapport with the interviewer.

The interview covered a wide range of areas that might influence energy use and was divided into groups of questions on related topics. Behavioral questions mostly concerned usual or typical actions, rather than possible changes made after the retrofit activity. The information collected in the interviews included the following:

- occupancy - household composition, time/duration occupancy patterns

- house - building characterization, dimensions, materials

- upgrades - retrofits, renovation, additions, appliances, motivations

- heating - equipment, practices, control schedules

- cooling - equipment, practices, control schedules

- water use - equipment, dish washing, laundry

- cooking and electronics - equipment, activities, timing.

Extensive notes were taken during the interview process, which were subsequently used in analysis to identify any patterns that might be associated with over- and under-savings in participant households.

\subsection{Contact Protocols}

Homeowner contact involved introductory letters sent to their homes, follow-up scheduling of interviews, and conduct of the interviews. These interviews provided important insights into homeowner behaviors, motivations, and satisfaction with completed retrofits.

\subsubsection{Introductions and Scheduling}

After potential cases were identified, they were grouped in batches for contact. The first batches consisted of roughly 20 households per mailing. Later in the study, smaller batches were sent out with higher frequency.

Initially, the first contact that a prospective participant would receive was a letter from the ETO asking for their help in a study and notifying them that a member of the research team would be contacting them by telephone. This letter was sent by the research team, but was on ETO letterhead and in ETO envelopes. The ETO has existing relationships with all of the participants and is a strong brand with a high level of trust and positive perception in the region. The letter is found in Appendix B.

When the response rates among those contacted in this manner were determined to be too low to support the study, an incentive system to encourage participation was adopted. Each participant was 
offered a $\$ 25$ gift card to a local establishment in exchange for participation in the study. A selection of cards from a number of vendors was offered as a means of obtaining a signature acknowledging receipt of the card, as required by the university for reasons of fiscal accountability. Gift cards were mailed within 2 weeks of completion of the interview and receipt of the selection form. The four gift card options provided were for a national "big box" chain, a national grocery chain, a local grocery chain, and a local fast food restaurant. While the gift card selections were not intended to be analyzed for relevance to energy use, proximity to the store seemed to be the strongest factor in card choice. No respondents opted for the restaurant.

Upon establishing incentives, the contact protocol was updated accordingly. Three additional items were added to the initial mailing, along with the letter from the ETO. These were a letter from the research team explaining the gift card, a form to select the vendor for the gift card, and a stamped, addressed return envelope for the form. This letter and form for the gift card can be found in Appendix C.

Study participants who had been interviewed prior to the inclusion of the gift cards in the ETO program were sent a separate letter thanking them for their participation and informing them of the gift card options. This letter contained the selection form and a stamped, addressed envelope.

Approximately 1 week after mailing the letter, a member of the research team phoned the primary contact phone number on record with the ETO to arrange an interview. As necessary, voice messages with contact information were left, alternate phones were contacted, and up to three attempts per household were made. The results of the calls were tracked on a shared online spreadsheet and scheduling of interviews was organized using Google Calendar.

\subsubsection{Interviews}

The interviews were scheduled to be as accommodating as possible for the participants. They took place as early as 8 a.m. and as late as 9 a.m., and were conducted on weekends as well as weekdays. The interviews ranged in length from 45 minutes to 2.5 hours. In most cases, the interviews were conducted in the home. Two interviews were conducted by telephone.

Interviews began with introductions, an overview of the study, explanation of expectations for the homeowner, and an opportunity to address any questions or concerns that the homeowner might have about participation. The basis for selection to participate in the study was not shared with the homeowners. Instead, some sample selection criteria were put forth with the caveat that the interviewer did not know what criteria the selection was based on. This was to ensure that neither the interviewer nor the respondent would be biased by expectations.

The interviews were primarily conducted seated at the dining room table or in the living room area of homes. Homeowners were encouraged to point out any changes that were made and any specific areas where the use of the home or specific equipment had changed as a result of the upgrades. 



\subsection{Results}

The statistical modeling and bill comparison analytical approaches yielded 80 total households that had consumption results that met the criteria outlined above. All households were contacted under one of the two protocols used in the study. Of the 80 contacted, 18 households agreed to participate in the study. Of these, the majority (13) were those that had been identified through one of the criteria for positive outcomes ("savers" in the discussion below). The other five cases are characterized as "spenders," whose post-retrofit consumption exceeded their pre-retrofit energy use (although, three of these turned out to be identified in error). This is not the distribution of cases that the research team had intended in its research design. As it turned out, "savers" were far more likely to respond to the survey request and agree to be interviewed, despite repeated attempts to solicit more participation from "spenders." Also, the research team discovered during the interviews that three of the "spender" cases were identified as such because of errors in the ETO program data files. Results from those cases are included in the reporting below for purposes of completeness, but are identified to prevent misleading conclusions.

Even for the "savers," actual savings were often lower than estimated. Differences between the estimated savings potentials and actual realization patterns found in the data, as well as findings from the interviews conducted with each household are discussed in the following sections.

\subsection{Savings Potentials versus Realized Savings}

While the research team's interview subsample was not intended to be representative of the entire program participant population, the team did explore possible biases in the subsample and found that the patterns of actual retrofits undertaken by case study households were, in fact, similar to the bundles of retrofits undertaken in the overall sample (Figure 3.1). The sample of 18 cases closely reflects the measures undertaken by program participants as a whole. The most common measures seen are air sealing and additional ceiling insulation. These measures are relatively non-invasive and thus pose lower upfront costs and attractive payback for homeowners. Other building envelope upgrades - insulation and duct treatments, - were also common in the sample and the population as a whole.

More expensive upgrades such as window replacement, heating equipment, solar, and domestic hot water installations were slightly more prevalent in the sample group than with program participants as a whole. In examining the trends in energy savings versus specific measures, no connection was found in the data between specific measures and higher or lower than projected savings. The savings projections for ductless heat pumps, however, are something of a curiousity. Savings model assumptions seem to be that this type of equipment will replace electric baseboard heat, thereby reducing electricity consumption. In practice, ductless heat pumps in this study replaced gas forced air, gas hydronic, and an oil boiler. In another instance a heat pump was added to a part of a house that was previously not conditioned. Ductless heat pumps are, of course, highly efficient solutions and it is important to support their movement into the marketplace. However, their treatment in this program induced considerable noise into our analysis. This noise is caused by the fact that program savings are recorded in units of the replacement systems energy source. So, for example, savings from replacing a gas or oil furnace with a ductless heat pump would be recorded as electricity savings when in fact, the conversion will cause a substantial decrease in gas or oil consumption, but an increase in electricity use. 


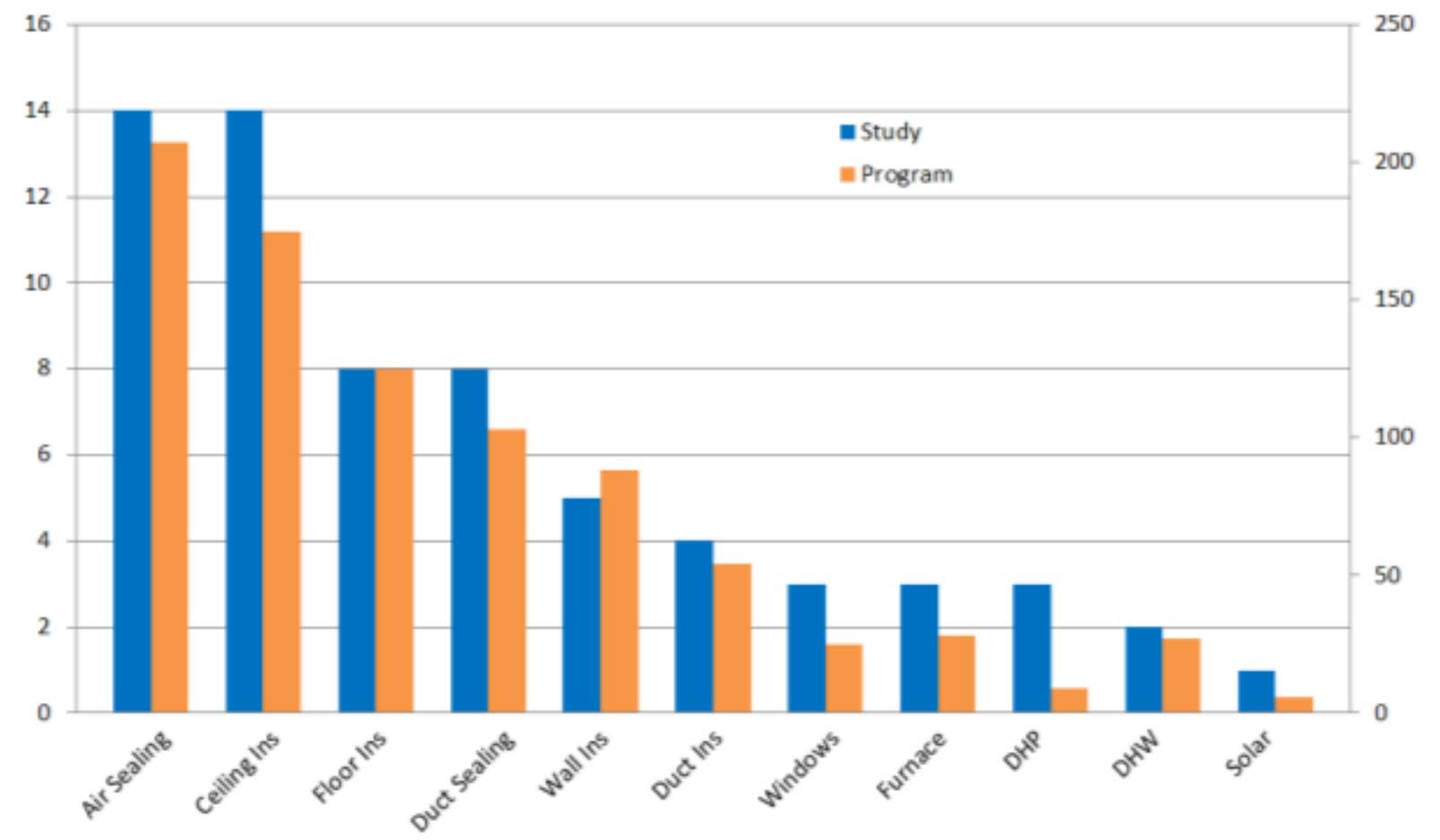

Figure 3.1. Comparison of Installed Measures, Interview Sample, and Program Population

It is useful to look more closely at the range of outcomes in the interview sample to explore "what" happened in these cases, and hopefully to better understand "why" the observed energy performance results are seen after the retrofits. When looking at the information in Figure 3.2 through Figure 3.8 below, it is easy to recognize that it would be useful to have similar information for the entire program sample. However, data access limitations placed on the ETO by the natural-gas and electricity utilities that provide billing information to the ETO prevented the research team from gaining access to that information.

The ETO shared the auditor-modeled projections of energy-savings potentials for each of the households in the interview sample. These are shown in Figure 3.2 as annual dollar savings estimates for each of the 18 cases in the sample. In this figure, the longer bars show larger projected savings.

Figure 3.3 shows the actual cost differences seen on the utility bills between the 12 months prior to the upgrades and the 12 months after the upgrades. The blue bars indicate a household that saw reduced utility bills. The red bars indicate increased household energy expenditure. The three lighter red (pink) bars indicate cases where the changes indicated are known to be in error. In two of these cases, the respondents reported during the interview that they had resided in the home significantly less than 12 months prior to the upgrade periods. In one case, the household switched from oil heat to an electric heat pump. Because the research team has no data on oil cost, it cannot correctly assess the change in utility bills between pre- and post- retrofit periods. 


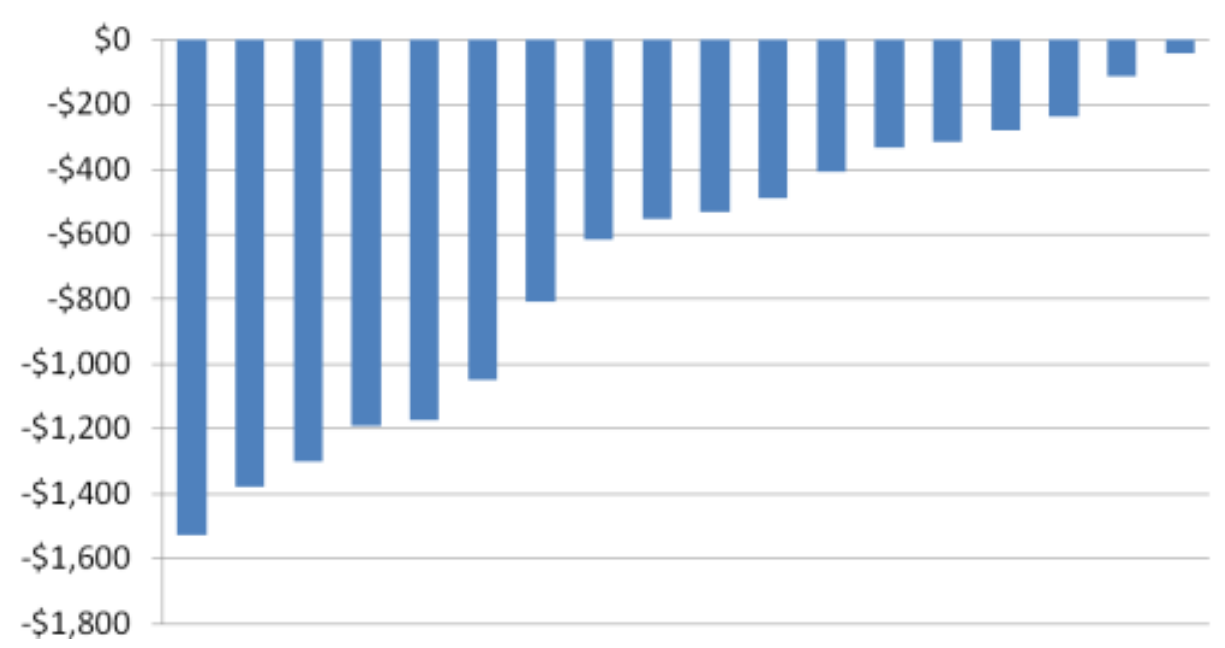

Figure 3.2. Estimated Annual Dollar Cost Reductions for Sample Households

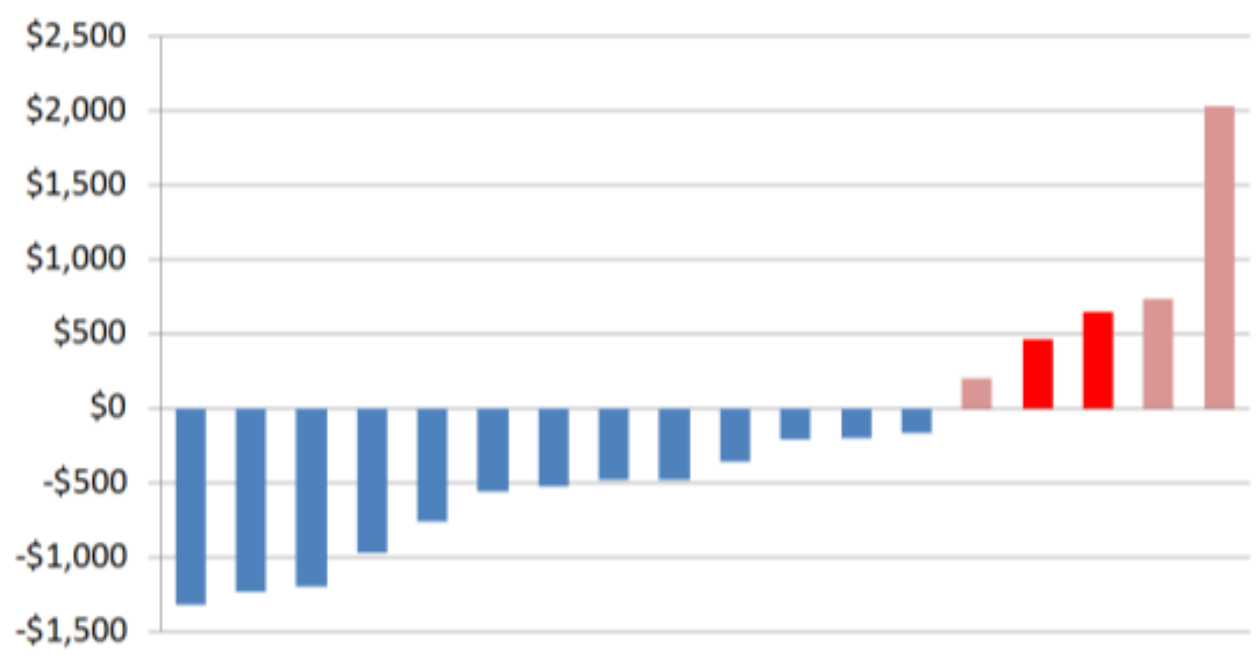

Figure 3.3. Actual Household Cost Differences (\$) Pre- and Post-Upgrade

Figure 3.4 combines the information in Figure 3.1 and Figure 3.2. It shows, for each household, the projected savings from the engineering estimates and the actual savings as calculated from the billing data. The sequence of the cases is arranged so that those with the largest projected savings are to the left. As in Figure 3.2, the cases where the "actual" data are known to be erroneous are included, but indicated by a lighter color. This graphic illustrates that the larger savings projections (to the left) were more likely to have fallen short of projections, while the more modest savings projections (to the right) were more likely to have exceeded them.

Figure 3.5 uses a graphical style similar to Figure 3.4, but now energy savings and consumption are disaggregated by type. The savings projections and cost changes are broken down into gas and electrical components. The projections are lighter in color than the actual savings, but with a consistent color scheme (gas=blue and electricity=orange). Again, the colors of the cases where the actual utility bills are known to be false are lighter. 


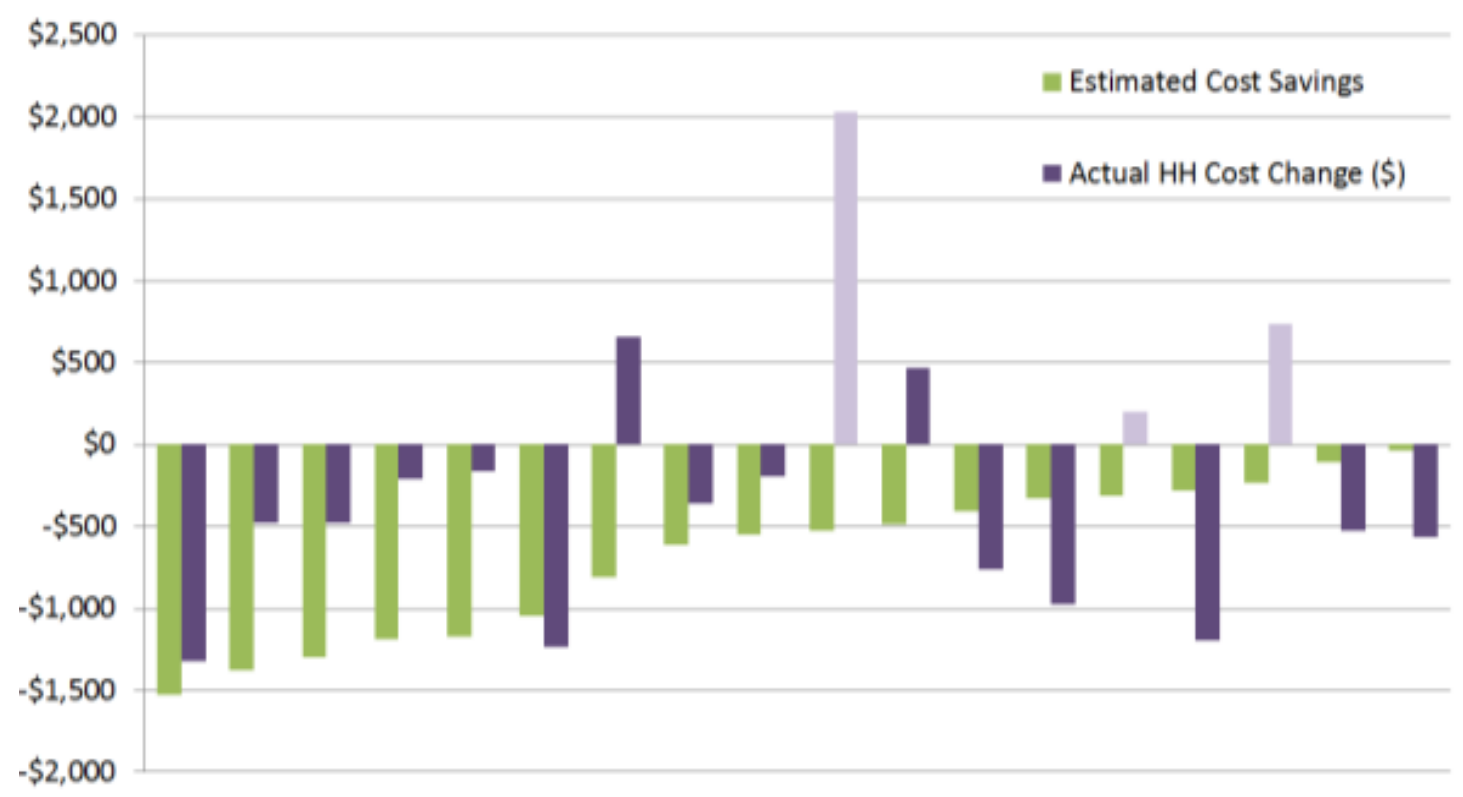

Figure 3.4. Household Energy Cost Savings Projections and Results

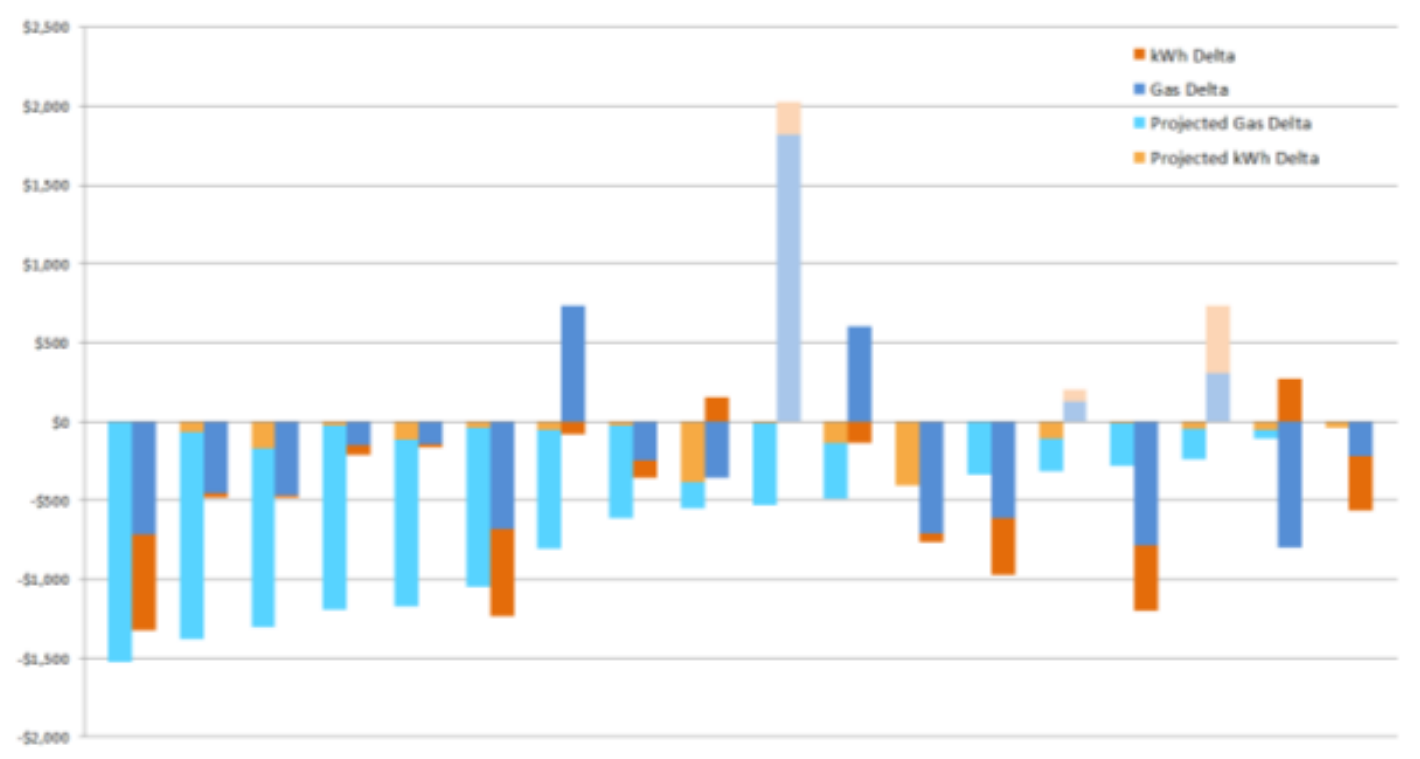

Figure 3.5. Household Energy Cost Savings Projections and Results by Fuel Source

This graphic shows how much more gas is projected to be saved than electricity. The projections are primarily blue, while the actual results are shown in blue and orange. Removing the cases known to be in error, for the remaining 15 cases the cumulative data are as follows:

\begin{tabular}{ll}
\hline Summary of Actual and Projected Savings & Value \\
\hline Projected aggregate gas savings & $\$ 9,703$ \\
Actual gas savings & $\$ 4,994$ \\
Projected aggregate kWh savings & $\$ 1,547$ \\
Actual kWh savings & $\$ 2,375$ \\
\hline
\end{tabular}


Actual natural-gas savings were approximately one-half (51\%) of projected natural-gas savings, while electricity savings were $153 \%$ of projected levels. In the aggregate, electricity accounts for $14 \%$ of the savings projections, but $32 \%$ of the achieved savings.

The previous comparisons have been made on an absolute basis. Because home size is an important factor in total energy consumption, it is also useful to examine the estimated and actual energy savings normalized by square footage. Figure 3.6 illustrates the energy consumption for each household in the study, in thousands of British thermal units calculated on a site basis, per square foot of the home. The sequencing of Figure 3.6 is different from the preceding graphs, with the cases presented in increasing order of pre-upgrade energy intensity. Cases that are known to have erroneous consumption data are not excluded and are indicated by the lighter coloring, as in earlier graphs.

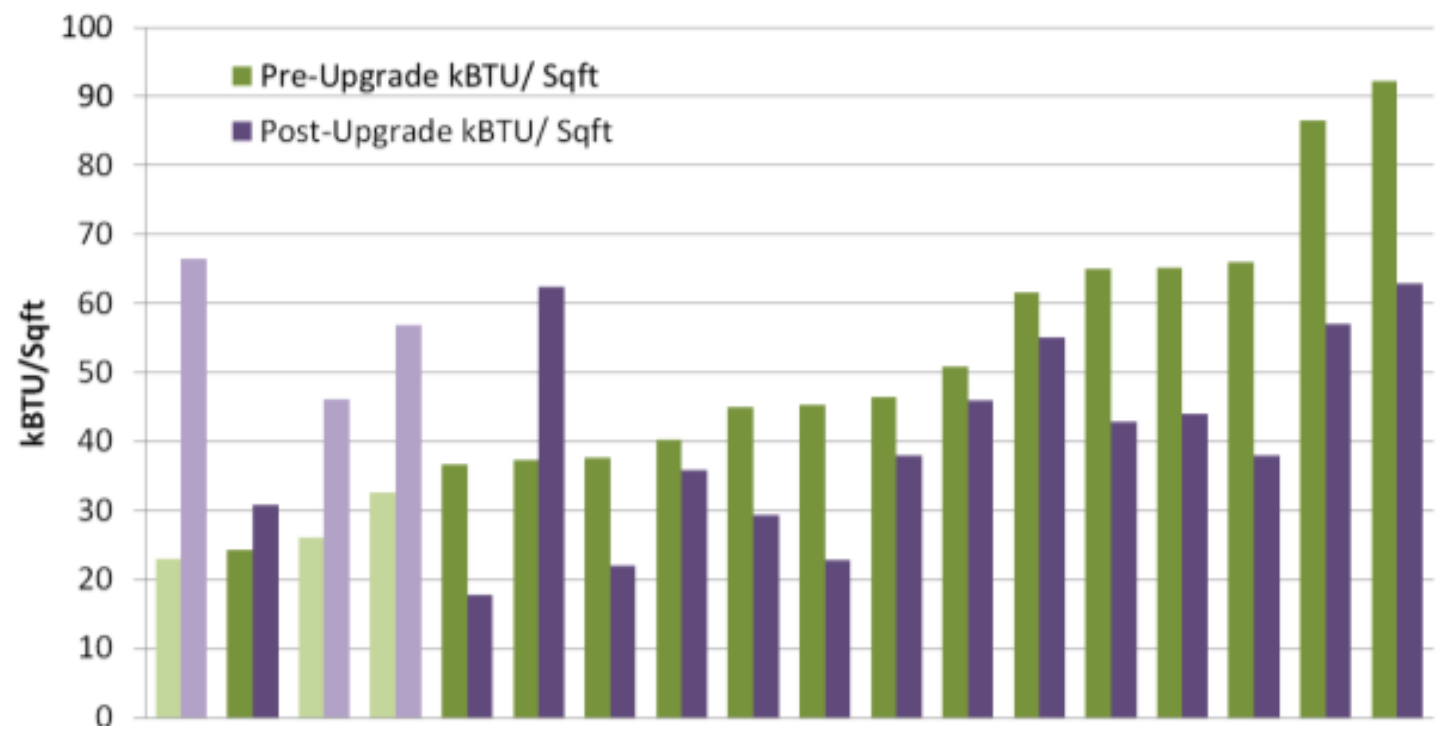

Figure 3.6. Household Energy Intensity - Interviewed Sample

Breaking down the household energy intensity by fuel type also provides some additional insights, as represented in Figure 3.7. It is of some interest that all households within the sample used some amount of gas, although based on the low level of gas use following the upgrades in some households the use was likely limited to cooking. In nearly all cases, decreases in both gas and electricity were evident. Cases where there were increases in electric use per square foot and a decrease of over $20 \mathrm{kBtu} / \mathrm{ft}^{2}$ in natural gas are indicative of a switch from natural-gas furnaces to ductless heat pumps.

Another way to look at savings across the subsample is in terms of the distribution of savings levels. Based on similar patterns or characteristics, the sample can be divided into five groups: 1) savings of $20 \%$ and greater than predicted by audit simulation, 2) savings within $20 \%+/$ - of predicted savings, 3 ) savings less than $20 \%$ of predicted, 4) increased energy use, and 5) cases with invalid consumption data. The research team found the following patterns when looking more closely at the distribution of savings levels, now categorized in Figure 3.8. 


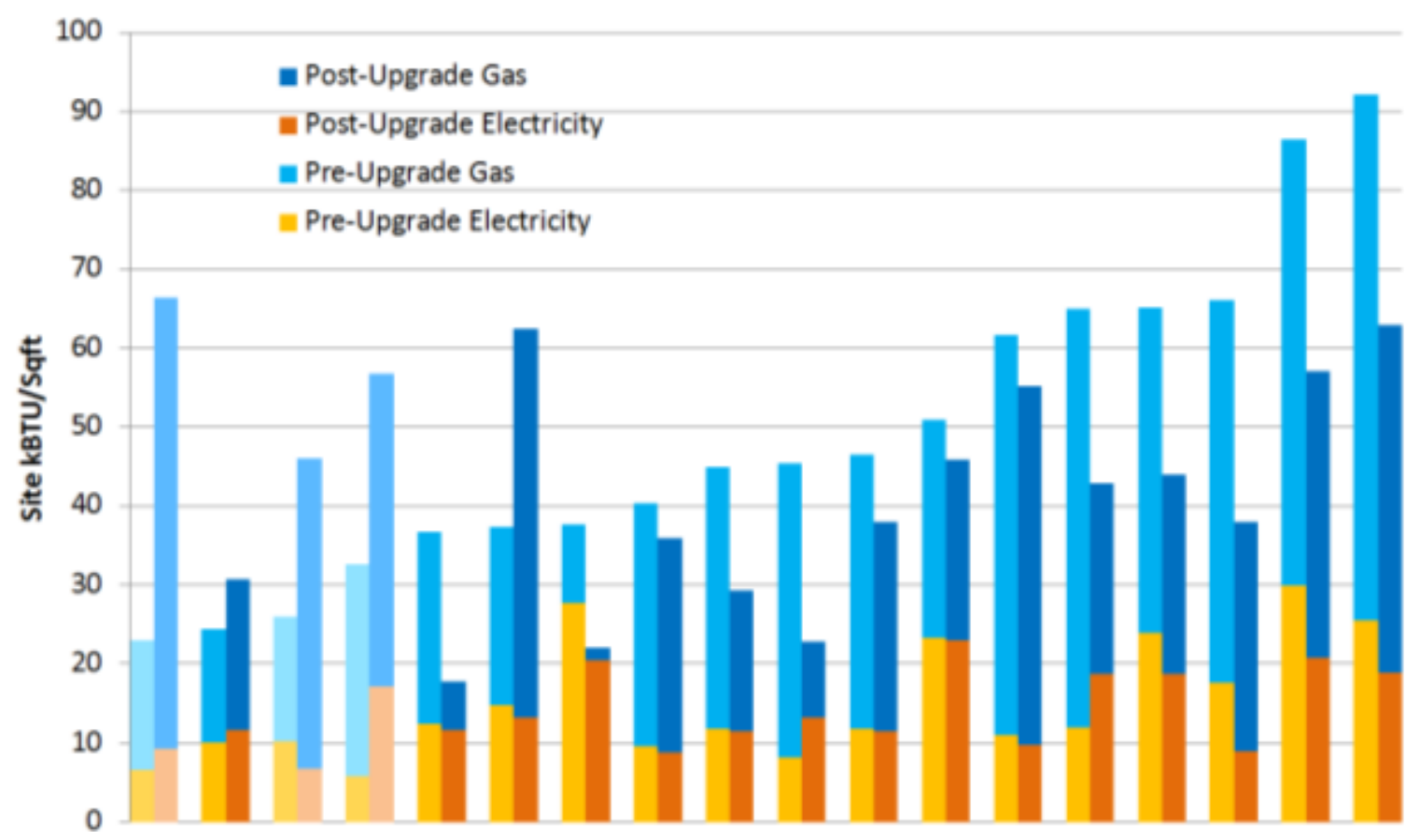

Figure 3.7. Household Energy Intensity by Utility - Interviewed Sample

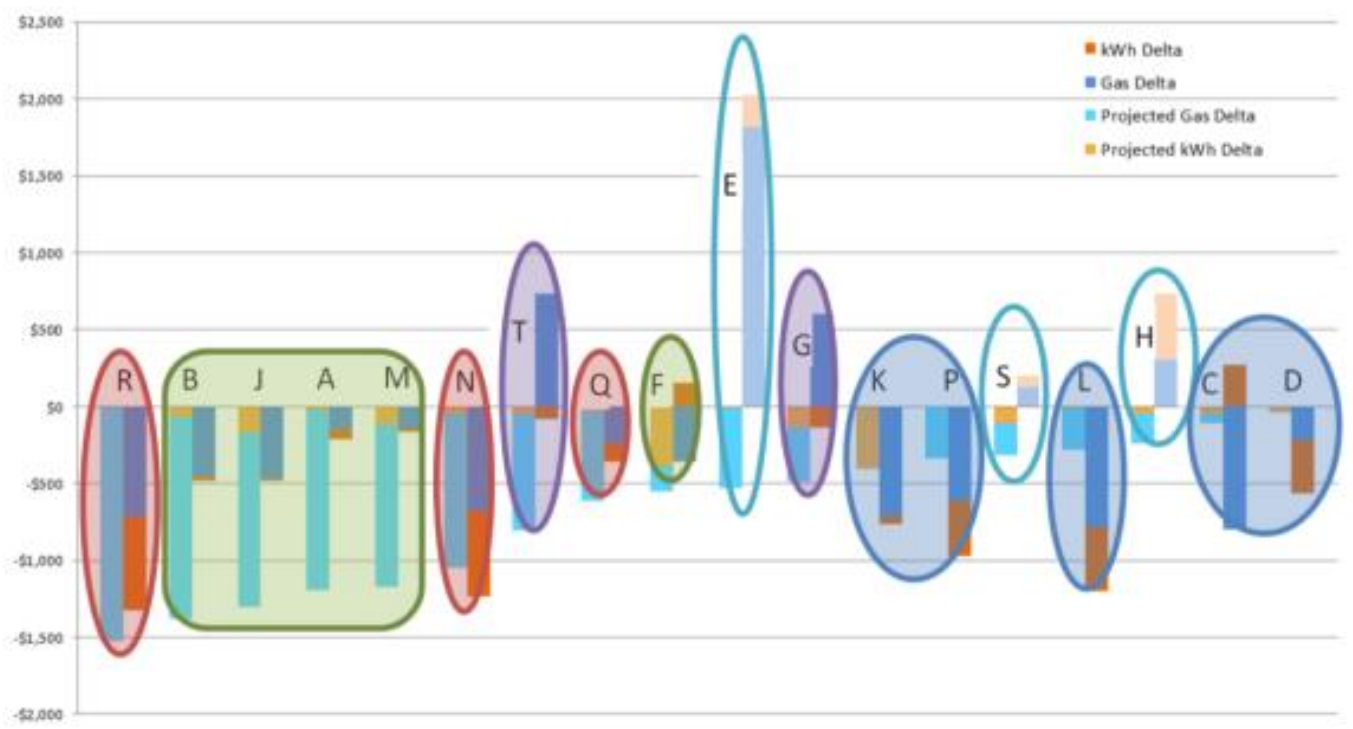

Figure 3.8. Estimated and Realized Change in Energy Cost by Fuel Source

\subsubsection{Savings $>20 \%$ Above Predictions (dark blue circles)}

There were five cases examined where the demonstrated savings were more than $20 \%$ greater than the engineering estimates provided. These cases, perhaps not coincidentally, had some of the lowest savings projections within the sample. Each of these households reduced its annual energy costs by more than $30 \%$. In four of the cases, nearly all of the savings estimates were of one fuel source, but substantial savings were demonstrated in the other source. 
Looking at information gathered through the interviews with the owners of these households in more detail provides insight into both how the savings may have been achieved as well as why the performance may have varied from the projections. In Case K, the performance reflects a conversion from a gas furnace to an electric ductless heat pump. However, the characteristic increase in electricity consumption is not observed due to the installation of a solar array, which complicates the analysis. The home in Case P used two heating systems - a gas furnace for the main part of the house and electric convection heaters in the secondary zones. This household also reported high air-conditioning use. The savings estimates from envelope improvements are only for the main heating system, not supplemental heating or air conditioning, which results in an underestimation of savings.

There was no clear cause for the discrepancy between the estimates and achieved savings in Case L. The homeowner did mention that the seasonal use of a swimming pool, with both filtering and heating requirements, had changed in recent years. For the last two cases where the actual savings greatly exceeded the estimated savings, the impact of fuel switching was not correctly projected in the estimates. In Case D, the savings associated with the ductless heat pump were reported as electricity, although that system replaced a gas furnace. The increase in electric use due to the heat pump installation was also confounded by fenestration upgrades outside of the ETO program. Case $\mathrm{C}$ is unique in that there was an offset in the dates of the conservation measures that contributed to the variation between projections and savings. The projected gas savings were from envelope improvements that happened months before the main heating system was upgraded from gas-powered forced air to a ductless heat pump. That heating system upgrade projected as an electrical savings despite increasing electrical use and reducing gas consumption.

There was a wide range of installation costs among this group of cases. The lowest installation cost was $\$ 1,400$, the highest was $\$ 44,000$. The latter was driven primarily by a photovoltaic installation. All five homes added ceiling insulation and three of the five underwent air sealing, illustrating the effectiveness of those measures. Ductless heat pumps were installed in two of these high- savings households, with the increase in electrical consumption being more than offset by gas savings and/or onsite generation. Most of these households had additional measures of some sort that were not part of the ETO program. In one instance, these were major upgrades - window and door replacements - but in four of the cases these upgrades were more subtle — blinds, light tubes, or fireplace conversions. These sorts of measures may be useful as indicators of acquisition or behavioral patterns that contribute to savings.

The interviews with these high-savings households also yielded interesting conclusions. Probably the most surprising was that two of the households added adult occupants during the study period. In both cases these were renters who were not members of the family. The motivations were varied among the respondents with environmental and sustainability concerns being prominently cited, followed by cost control and improving home comfort. Each of these households used multi-zone programmable thermostats and two of the five reported regularly turning off the heating system each time they left the house. Also, interestingly, two of the households reported that at least one member was frequently uncomfortable with the temperature settings used in the thermostat program. This was a particularly poignant example of conscious sacrifice made to save energy. 


\subsubsection{Within 20\% Plus or Minus of Predictions (red circles)}

Relatively few cases in the study had performance that nearly matched the engineering estimates, that is to say, the demonstrated savings within $20 \%$ of the projections. The three cases where the projections matched outcomes were some of the cases with larger projected savings, and two of the three achieved greater than $30 \%$ household energy cost reductions. While these appear to be accurate projections, when broken down by fuel source, nearly all of the projected savings are estimated to be in the form of gas savings, while the demonstrated savings appear roughly split between gas and electricity. This may indicate that underestimated savings from the heating system are being compensated by air-conditioning savings from envelope improvements, which are not currently included in estimates, additional retrofit measures, or behavioral changes.

All three of these households had both air sealing and duct sealing performed as part of the ETO program. The two that achieved over $30 \%$ savings also had comprehensive envelope upgrades, including ceiling and floor insulation as well as duct insulation. Each of these homes also had multiple appliance upgrades. These more comprehensive energy retrofits cost on the order of $\$ 5,000$ in total. One of the two homes also pursued major and minor measures outside of the program (windows, blinds, light tubes).

Each of the households cited cost control as a factor in performing the upgrades, with two listing it as the sole reason. Comfort and sustainability were also cited by a single household. The occupancy of these homes was stable over the study period, with only a single additional temporary adult resident being reported in one home. These households reported a wide range of home heating control behaviors. For example, one home maintained a constant temperature regardless of occupancy or season, while another used a multi-zone thermostat program that was turned off when the house was empty.

\subsubsection{Savings $>20 \%$ Below Predictions (green circles)}

Five of the 18 cases achieved savings that were less than $20 \%$ of the engineering estimates. All of these were among the cases with the highest projected savings and they all achieved significant energy reductions, although not to the ambitious levels that had been projected. One household reduced energy costs by more than $30 \%$, but still fell short of the ambitious engineering estimates. While on the chart the performance of these cases appears similar, on closer examination there is little in common between them.

All but one of these cases performed at least five energy conserving measures. Attic and floor insulation were the most common measures, followed by furnace replacement, hot water upgrades, and air and duct sealing. Two of the homes also installed high-efficiency appliances. There was a wide range of upgrade expenses in this group, ranging from $\$ 1,400$ to $\$ 14,000$, with an average of $\$ 7,500$. At the low end of that spectrum, the home that had the fewest measures - air and duct sealing — saved the least energy of this cohort, with less than a $10 \%$ reduction in household energy costs.

These households cited energy cost control and sustainability as the primary factors in pursuing the upgrades, although none had analyzed the performance based on billing data. Occupancy changes that would contribute to increased energy consumption were common themes throughout this group. In two cases, the households not only added members, but increased heating patterns to accommodate the new members. In one instance, the homeowners had a child and in the other an elderly parent moved in. In 
two other cases, members of the household began working from home during the post-upgrade period. These factors probably contributed to the homes not meeting their savings estimates.

\subsubsection{Increased Energy Use (purple circles)}

Two of our cases exhibited increased energy use in the year following the upgrade compared to the preceding year, in spite of substantial upgrade activity. In both instances, there appeared to be factors that would explain the increase in consumption. In the time prior to the upgrades both households had been single occupancy homes. In one case, the lone resident retired concurrent with the upgrades. This had the effect of increasing lighting and utility loads, as well as altering the set points of the thermostat program. In the other case, two adults returned to live in the home, increasing the number of residents threefold.

\subsubsection{Cases Involving Erroneous Pre-Retrofit Utility Bill Data (not circled)}

During the interview process, three cases were determined to have been identified based on erroneous data. In each of the cases, the interview continued, because even without consumption data for the full pre-intervention periods, the cases provided context for the sample as a whole. In two of the cases, the homeowners reported moving into the home less than 6 months prior to beginning the upgrade activities. The presence of billing data for a full 12 months prior to the upgrades for each of these homes is mysterious, because the stated policies are for the accounts to be neither transferred between domiciles or account holders. It is not clear which of these led to the errors. In the other erroneous case, the upgrade included switching to a ductless heat pump from an oil furnace. Because we do not have any oil consumption data, the increased electrical consumption is misleading.

\subsection{Recurring Themes in the Interviews}

Within the topic areas that were covered during the course of the interviews, a number of themes emerged. The research team used these themes as they emerged to help shape the interviews and data collection.

\subsubsection{Occupancy}

Changes in household occupancy can have notable effects on energy consumption. While in general an additional occupant increases energy consumption and a reduction in occupants decreases household consumption, it is more difficult to assess the magnitude of the change.

Some occupancy changes can be expected and planned for by residents, such as a teenage family member leaving for college, while others, such as a relative moving in due to medical issues or displacement by natural disaster, cannot be predicted. These changes can have significant effects on household energy use, making savings appear or disappear in the data, regardless of changes made to the dwelling.

Not all changes in occupancy are complete changes in the number of residents in the home. The patterns of how individuals inhabit their dwellings can also change in ways predictable or not. For example, entering or leaving the workforce is a life change that is made without consideration of energy impacts, but which has ramifications on the apparent savings that can be achieved. The increasing trend of professionals working from home also has an impact on both thermal and plug loads that can cloud the appearance of savings. 


\subsubsection{Thermal Control}

The most basic element of thermal control behavior is the temperature set point. On this question alone, there are many variables to consider: what type of thermostat is used (e.g., programmable vs. manual), how is the thermostat managed (e.g., whether it is at a constant temperature, manually adjusted, or running a program), and, beyond those considerations, is the operation of the heating or cooling system manually switched. Also interesting are the social aspects of home temperature management: whether different members of the household operate the system differently - the so-called "thermostat battles" and whether members of the household have made a conscious decision to maintain temperatures outside of the what they consider to be comfortable, in the interests of decreasing energy use or costs.

Active management of the home's thermal environment can also take the form of controlling the solar gain or ventilation of the home. In the winter, some households regularly open blinds by day and close them at night to maximize the solar gain. Conversely, a number of households stated that during hot periods, they left windows wide open overnight and shut the windows with blinds drawn prior to sunrise. Maintenance of heating and cooling systems, tunings, and especially changing or cleaning of filters is an area that warrants examination. It is a slight exaggeration to say that households tend to fall into one of two categories: either the thermostat has a setting that reminds them to change or clean the filter, or they wish that they remembered more often.

\subsubsection{Window Upgrades}

Window upgrades proved to be one of the more interesting and confounding measures over the course of the study. Of all of the building envelope measures, windows are the most visible and have the most obvious non-energy characteristics. Discussion of windows featured prominently in a number of interviews, whether or not they had been upgraded as part of the ETO program. In a number of interviews, homeowners pointed to windows as being the cause of comfort issues, with cold air seeming to radiate from the legacy windows.

Three of the homeowners stated during the interview that they had upgraded the windows as part of the ETO program. However, upon reviewing the records provided by the ETO, the team found only one of them had window measures on record. This finding indicates that window improvements undertaken in these homes, whether incentivized or not, are not included in their savings estimates.

In the cases of homeowners who opted to upgrade the windows, the decision was based on increasing the resale value of the home. Windows were the only measure for which this was the case. The decision to upgrade windows seemed to have a separate calculus entirely.

Window replacement was also the most frequently cited audit recommendation not to be acted upon. The most common reasons cited for not upgrading windows were the high upfront cost and long payback period. Homeowners stated that they understood costs to be in excess of $\$ 10,000$ and payback periods of over 20 years. While payback was rarely cited as a deciding factor in pursuing any measure, it clearly deterred homeowners from replacing windows. In one instance, aesthetic concerns with replacing period windows with modern, high-performing windows was cited as the reason for not pursuing a window upgrade. Older research has suggested that homeowners often gravitate toward window replacement as an energy-efficiency measure (Stern 1992). Now that homeowners are more aware of payback periods for window replacements, perhaps this knowledge has actually deterred window replacements that might otherwise take place. 


\subsubsection{Domestic Hot Water}

Similar to lighting and thermal control, the evaluation of domestic hot water (DHW) use relies on similar ways of classifying the level of active behavioral control that households exercise over this utility. Like heating or cooling, DHW temperature is controlled through a one-time or at least seldom-changed setting. Unlike central heating and cooling, hot water temperature settings are rarely seen and the resolution is crude. It is exceedingly rare for households to have much finer resolution on temperature settings beyond "too hot" and "not scalding." Households appear far more likely to use lower settings not out of concern for reducing energy use, but as a safety concern, particularly when there are children or senior citizens residing in the household. On the other hand, there are also public health admonitions not to set water-heating temperature too low (Brazeau and Edwards 2012) — and with which energy conservation recommendations sometime conflict.

Variations in the consumption of hot water are exceedingly difficult to accurately gauge through survey methods - homeowners may not be able to accurately report bathing or other hot water use activity, which can be extremely varied, and even if these could be precisely reported, the energy and water use implications may be highly uncertain. A more telling aspect of hot water behavior may be whether homeowners report turning down water heater temperature, or using the vacation setting on the water heater, when leaving home for long periods of time.

\subsubsection{Habits and Rational Calculation}

It is commonly observed in residential energy-use and energy-efficiency analysis that a considerable amount of routine consumption is habitual, and therefore unconscious or invisible to consumers (e.g., Maréchal and Holzemer 2011). Short of direct observation (which can, itself, alter behavior), researchers and evaluators are forced to rely on persons' self-reports, which are understandably inaccurate. There are undoubtedly a wide variety of habits that result in large differences in patterns of energy use. Some of these can be considered "active management" (of window coverings, lighting, temperature levels, etc.), while others are indicated by more subconscious choices, such as indoor "thermal preferences," "water draw patterns," etc. However, a large class of behaviors is related to cultural practices and individual habits that are undoubtedly important to both consumption and conservation, but are much less commonly discussed in energy analysis - e.g., cooking patterns, cleanliness standards, coziness expectations, exuberant or cautious socialization, etc. Our current instruments are not designed to detect these patterns, but our onsite interviews allowed at least an intuitive sense that residents were living a range of lifestyles that would have implications for their energy-use levels, with a number of the high-savings cases involving homeowners who seemed to be at least somewhat vigilant about the energy implications of their actions.

In opposition to the idea of habitual consumption and control, is the notion that consumers are, at least sometimes, quite aware of and intentional about their energy use, particularly when faced with energy prices that they consider high or expensive. However, no homeowners interviewed said that they tracked energy costs or used them to assess the effectiveness of upgrades. This was particularly striking among the households that identified cost control as a prominent reason for pursuing the upgrades. Price fluctuation and lack of familiarity with the terminology and units were cited as reasons for not being able to track and judge the effectiveness of upgrades in controlling costs. Whether the new attention to easyaccess energy-use information will lead more people to actively track energy and critically assess the success of any energy upgrades performed is an open question. 


\subsubsection{Motivations}

Households pursue energy-efficiency upgrades for a variety of reasons, and often several motivating factors. That is to say, upgrade decisions are not only based on multiple considerations, but different factors can be weighed differently in relation to different upgrades. For example, a household may concurrently pursue envelope and appliance upgrades and base the decisions on different considerations/rationales. The research team's interviews sought to explore whether it was possible to identify any relationship between the nature and priority of the motivating factors and the realization of projected savings.

The commonly cited motivating factors were both "financial/ utilitarian" or what we might call "personal/cultural." Some of the financial motivations were predominantly economic decisions or involved necessary replacement of non-functional equipment. The financial factors cited were cost control and home value. In these instances, homeowners gathered information, often from multiple sources in efforts to reach informed decisions. This is more straightforward for billing cost control than for assessing the impact of upgrades on home values, which is far more nebulous. Homeowners citing the impact on home value as a factor tend to view this as either an article of faith or base the assertion on sales comparisons.

However, many home energy upgrade decisions are not based upon analysis of expenditures, incentives, and projected future returns. The most common personal/cultural factor cited for opting to pursue energy upgrades is comfort, specifically related to temperature control. Conversely, the subjective factor likely to be cited as a reason not to pursue an upgrade or use a more efficient alternative is aesthetics. This is particularly true of lighting, with the "quality" or "warmth" of the light provided by incandescent or halogen bulbs often being preferred. The incongruous appearance of newer windows in homes of older vintage was also cited as a reason not to pursue window replacement. While there were complaints about the level of comfort provided by ductless heat pumps, they were not cited as reasons to not install that type of system.

Another personal reason for pursuing energy upgrades is the belief that doing so would further broad societal, environmental, or sustainability goals. Within the study sample this motivation was common, but particularly notable in two instances. The first was that parents were likely to articulate this motivation in terms of their children, either in setting an example of how to act or evoking the impact of energy on the environment over future generations. The second way that environmental concerns surfaced was a disproportionate concentration of "sustainability professionals" in the sample. These were individuals working as architects or energy consultants who expressed interest in cultivating better understandings of building science and energy use as well as a desire to "practice what they preach."

\subsubsection{Appliances and Equipment}

Home electronics and computing, or miscellaneous electric loads, are areas of home energy use that have become a new focal point for the development of technology-centered codes and standards to reduce energy consumption. In particular, televisions and personal computers have received a great deal of attention and have seen marked improvements in the efficiency of new equipment. Beyond replacing the equipment or adding external power-management capabilities, how and how much these types of devices are used is of considerable interest. Behaviors of interest include the use of active power-management settings or simply manual power control on computers. Peripherals may be controlled using various levels of power strips, ranging from simple surge protectors to smart strip units that sense draw from a primary appliance and control power to other outlets accordingly. 
For electronics equipment, one of the areas examined was how "standby power" or "vampire load"power that is constantly drawn even when the equipment is not otherwise actively in use-was managed, if at all. Participants were asked how often they used various types of equipment and whether items were unplugged or power strips turned off. The amount of standby power used varies considerably by residence and is not well known, but one small-sample study estimated that consumption ranged from 14 to $169 \mathrm{kWh}$ and $5 \%$ to $26 \%$ of a household's total power consumption (Ross and Meier 2000).

Choices and use of major appliances were discussed through the interview process. A number of appliances, such as refrigerators and clothes washers, were eligible for incentive payments through ETO programs. In some cases energy use was a deciding factor in the selection of appliances. However, the appearance of appliances, especially kitchen appliances, and cost were the most common deciding factors. With respect to management of vampire loads, homeowners used a wide variety of management strategies. Many homeowners did not use active strategies to manage vampire loads, while others unplugged most appliances while not in use. These conservation tendencies typically were associated with thermostat and lighting control behaviors.

\subsection{Characterizing "Savers" and "Spenders"}

As noted, the interview cases represent a very self-selected and homogeneous sample of residential energy users. For purposes of analysis, however, they can be roughly categorized as "savers" and "spenders." "Savers" are defined as those households that used less energy after retrofits and "spenders" are defined as households that used about the same amount or more after upgrades had been completed. While the motivations and actions of these groups are in many ways similar - a somewhat surprising and ironic, but nonetheless interesting and potentially important finding-some observed differences are worth noting.

\subsubsection{Spenders}

A common and wholly explicable factor found in households that had not met savings projections after retrofit activity was increased occupancy. There are a variety of potential reasons for this occurrence, including, but not limited to rental income and family support, medical or otherwise. Simply put, additional occupants in a house lead to increased use of utilities at a basic level. This can be accentuated in the case of occupancy changes resulting from medical need due to medical equipment or highly constrained thermal requirements to maintain comfort. Of the five households demonstrating energy consumption above expectations based on historical use and estimated savings, three had additional occupants beginning after the start of the upgrade period (having renters or adult family members joining/rejoining the household).

In some of the households that did not realize the expected savings, one of the contributing factors might have been that these homes pursued piecemeal retrofit strategies. In these homes it was noted that while building envelope improvements or fenestration replacements were performed, large windows were not upgraded. In these instances the windows that were not replaced were single pane and were identified as comfort issues by the residents. In one instance the homeowner reported both draft and condensation issues emanating from the old bay window. It is difficult to assess the impact of this factor on energy savings, because it was present in conjunction with an occupancy change. The other instance where incomplete envelope upgrades may have played a role in realization of reduced savings involved a set of six single-pane windows approximately $12 \mathrm{ft}$ wide and $16 \mathrm{ft}$ tall. The residents reported continuing 
comfort issues in this room even after sealing leaks in the rest of the house. The issue was described as temperature stratification with differentials estimated at 10 degrees between two levels of the house.

While difficult to characterize, there was an underlying, and sometimes expressed, sentiment among those whose retrofits had failed to realize savings that the physical upgrades alone would lead to energy savings. Occupants in this cohort did not seem to recognize that habits can also drastically increase consumption, rather than relying only on the hardware upgrades to enable reductions in consumption. It was notable that the upgrade activities among the underperforming households were on the whole more likely to be piecemeal and incomplete - as opposed to the high-savings households where the upgrades tended to be more comprehensive and supplemented by additional, un-incentivized measures and actions.

The response rate of households with lower than anticipated savings was particularly low. This may have resulted from their lack of desire to revisit the topic, or from the fact that at the time they were invited to participate, no gift was offered as compensation for participation in the research study, because this group of participants was contacted prior to any incentive structure being in place.

A common motivation for upgrades cited by individuals who had not realized projected savings was increasing home value. It is worth noting that this was somewhat specific to window upgrades. Market value is particularly difficult to gauge, especially in the absence of an actual home sale. In all cases where home value was cited, however, the respondents stated that they felt the improvements had contributed to the home "holding its value." A potentially insightful opinion voiced by one of the individuals who had undertaken deep energy retrofits (projected greater than $30 \%$ of household energy cost) was that "the appraising community was not savvy enough to judge the value of energy upgrades." That said, the impact of window improvements on home value is primarily due to aesthetics, rather than any calculation of the effect of upgraded windows on future energy costs.

\subsubsection{Savers}

In the households where sizable savings were achieved a number of traits were commonly noted. Perhaps most noticeable among these was a common tendency to couple energy-conscious actions and behaviors with hardware changes. These households were more likely to use the programmable features on their thermostats, and turn down hot water heaters and/or unplug electronics when traveling. Unfortunately, we were not able to determine when these behaviors started (i.e., before or after the retrofits) - an obvious topic for future research.

Also, beyond the incentivized upgrades for these households, evidence of supplementary upgrades was found in other areas independent of incentives. Examples of these include insulating blinds, light tubes, and thermally insulating doors. In some instances, water-saving measures such as low-flow toilets were also undertaken. Reductions in occupancy also had clear impacts reducing energy consumption. In cases where occupancy had decreased during the intervention period, large savings were observed.

The most common motivation for pursuing energy-efficient upgrades among top-saving households was improving thermal comfort (rather than saving energy). Households largely reported that the upgrades were successful in improving thermal conditions, with temperatures being more agreeable, drafts reduced, and large temperature swings removed. A number of respondents claimed to turn off heat every night since envelope upgrades, and in two cases they left windows open overnight year-round. One respondent did express some disappointment with the comfort quality of the heat provided by a ductless heat pump. 
A potentially surprising observation was that there is no discernible difference in lighting preference between households that realized higher-savings levels and others. While the behavioral tendencies showed more conscientious patterns among the savers, all individuals interviewed had undergone extensive audits and upgrade activities, suggesting an elevated concern about energy conservation (for whatever set of reasons), with lighting a highly "visible" (and programmatically promoted) option. However, every home in the study had a number of bright (greater than $100 \mathrm{~W}$ ) incandescent and/or halogen lights. This shows that aesthetics do matter, even to individuals highly concerned with saving energy. A majority of the respondents with high levels of energy savings expressed a desire to have an impact on the future from an environmental sustainability standpoint.

As shown in Figure 2.3, our sample of 18 cases closely reflects the measures undertaken by program participants as a whole. The most common measures seen are air sealing and additional ceiling insulation. These measures are relatively non-invasive and thus pose lower upfront costs and attractive payback for homeowners. Other building envelope upgrades - insulation and duct treatments - were common in the sample as well as the population as a whole. More expensive upgrades, such as window relacement, heating equipment, DHW, and solar installations, were slightly more prevalent in the sample group than with program participants as a whole.

\subsection{Key Conclusions}

This study analyzed the behavior patterns and motivations of homeowners with regard to home energy efficiency after retrofits in their homes. Through analyzing utility bill data to characterize realized savings; retrofit data to describe the type, cost, and expected savings of retrofit measures; and homeowner interviews to explore the impact of occupant behavior on retrofit savings, this research sought to identify common traits and factors that appear to influence the success of a home energy retrofit in achieving significant realized savings. The following observations were noted during the study process:

- It seems to be particularly difficult to interview program participants whose experiences have not met expectations.

- Households are not monolithic in their energy consumption or conservation.

- A diversity of savings levels can be realized by households installing similar measures.

- Actual savings and predicted savings levels may be quite different.

- Motivations for pursuing energy upgrades are varied and were not strongly influenced by cost-savings potentials in the 18 cases studied.

- Occupancy, thermal control practices, and habits all seem to contribute to consumption and conservation in ways that are not actively addressed by retrofit program activities.

- Households that practice active behaviors to control energy costs in addition to pursuing upgrades may achieve higher savings and levels of satisfaction with the upgrades.

- Pursuing and achieving savings does not come at the cost of wholly foregoing comfort, aesthetics, or convenience.

- Savers and spenders exhibit different patterns of behavior and non-program-induced investment. 



\subsection{Lessons Learned and Future Research}

This research was unusual. Despite the many home energy upgrade programs nationwide, detailed household-level analyses are rare and differences between projected and realized savings seem generally to be overlooked (except in aggregate estimation and largely abstract discussions of "rebound" effects). The research reported here shows that much can be learned from careful examination of household decision-making and behavior. It revealed numerous challenges to fulfilling even a carefully constructed research plan when working with homeowners. One of the positive outcomes of a project that encounters as many obstacles as this one did is the opportunity to identify issues and discuss what might be done to avoid them in future efforts, as discussed in more detail below.

\subsection{Challenges in Accessing Program Data}

Obtaining access to the ETO program data was far more challenging than anticipated during project planning. Both receiving clearance to be able to analyze the data and the manner in which the analysis needed to be performed significantly delayed the study. A particular point of contention was the requirement of individual and organizational indemnity as condition of access to the billing data. Because these data are considered personal customer financial information, the utilities are duly concerned with maintaining confidentiality and the indemnity is a means to this end. However, state laws place finite limits on the punitive measures available to state universities and their employees. Ultimately, this issue was resolved by employing a third-party firm that had the necessary agreements in place and was experienced in handling data from the ETO and utilities.

As part of the agreement that enabled use of the billing data, members of the research team were not able to work with the data directly. This led to a number of difficulties in performing analysis, because the loops to verify performance of the scripts written to identify outlying results could not be easily checked. This lack of diagnostic capability led to a fair amount of wasted effort, because issues were usually not discovered until full runs of the software programs had been executed. This led to increased development cycles, because some iterations of scripts did not yield any particular insight.

\subsection{Discovering Data Limitations}

Upon reaching agreements enabling access to the data, the research team found that the population was smaller than initially anticipated. This may have been a simple miscommunication about the total number of participants in the ETO program as opposed to the number of participants that met the timeline outlined in the selection criteria, namely sufficient time following the upgrades to assess their effects. Rather than selecting a sample from a population of thousands of cases, there were a few hundred. Additional filters applied to this group, such as a common weather reporting station and a full year of billing data before and after the upgrade period, further reduced the sample from which cases could be drawn.

\subsection{Homeowner Reticence Relative to Being Interviewed}

The gathering of information from homeowners started out much more slowly than anticipated. Coming on the heels of the delays associated with data access and analysis, this was very troubling. The first groups of program participants contacted responded at a rate below $10 \%$. This was a marked 
departure from what had been expected based on previous ETO program experience. Because the population was already smaller than had been expected at the start of the project, the research team needed to obtain a higher response rate in order to develop a useful sample set.

Through discussions with other researchers at the university, it was decided to offer a gift card to participants as an acknowledgement of the time involved in participating in the study. It took roughly a month to develop and document the process for dispersing the cards and apply for and receive approval from the Human Subjects Research Review Committee. The inclusion of gift cards in the process contributed to the positive response rate increasing from below $10 \%$ to above $60 \%$.

There were exceptions, but generally, an hour seemed to be roughly the amount of time that homeowners were willing to commit to participating in the study. This was made apparent both in the scheduling and conduct of interviews. This placed some limitations on the extent of data gathering that was possible. Lacking access to the ETO program audit data or modeling information, it would have been very useful to gather a wide range of building information for the study through a thorough home audit. Pressing this would have risked further lowering participation rates. Two approaches — offering higher incentives and splitting the time over multiple visits - might increase the possibility of more time onsite and more detailed information gathering. These approaches could be used together.

\subsection{Losing Most of the Cases with Low Savings}

When the research team began recruiting interview participants, it focused on recruiting households that had either experienced less than expected savings or outright increased energy use after the upgrade activity. As explained above, these households were largely not interested in participating in the research. In subsequent recruitment, the team offered potential participants a gift in compensation for their participation in the study. However low-saving individuals may have had a disappointing experience with their upgrade activities and were less inclined to participate, with or without compensation.

The research team started with a smaller than anticipated population; even being fairly liberal in its interpretation of what would constitute interesting cases, there were far fewer cases than the team had hoped for. With a smaller sample, the focus necessarily shifted to a more in-depth contextual approach. That is, the team traded breadth for depth, in an attempt to develop richer insights.

\subsection{Database Problems Discovered During the Interview Stage}

Some households that were identified through statistical modeling as having particularly high or low fuels-specific savings were later discovered to have undertaken fuel supply changes. In later analyses, the team analyzed savings in terms of household energy cost. This was effective in most cases, although fuels outside of the participating utilities were not captured. In the future, total source energy use or household energy cost might be better variables by which to assess savings achieved for these houses than the single fuel modeling used early in this study.

\subsection{Uncooperative Weather for High-Quality Thermal Imaging}

The most common measures in the ETO program pertained to the building envelope. One of the desired means of assessing the effectiveness of these measures was thermal imaging. Unfortunately, due to the temperate climate of the Portland area, the temperature differentials between usual indoor and 
outside temperatures are rarely great enough for optimal thermal imaging performance. The months that temperatures would frequently allow for effective imaging are December and January, which coincided poorly with the timing of this study.

\subsection{Future Research Possibilities}

As an exploratory study, this research demonstrated significant deviations in actual realized savings from formal modeling predictions. While aggregate forecasts of energy savings quite likely produce "good enough" estimates of savings potentials — good enough to confirm the notion that investments in building upgrades will, for the most part, yield energy savings - the research team saw that the magnitude of savings can vary widely across samples of homeowners and from auditor projections. The differences are often large enough to make a substantial difference in the energy-savings cost-effectiveness of the measure, from the point of view of the homeowner. Overestimates of savings may lead to homeowner mistrust or disappointment in energy-efficiency upgrades more generally. A priori underestimates of energy-savings potential may dissuade homeowners from undertaking upgrades that would actually be effective. Of course, the reasons for these underestimates and overestimates may be due to inaccuracies in recommendations or installation.

The research team also saw that at least some of the causes of deviation from expectations are attributable to the dynamics of consumption, which are, in turn, strongly affected by the dynamics of everyday life (occupancy/household composition, habits, comfort preferences, etc.), as well as the dynamics of housing upgrade/renovation (bundles of features added, synergies from multiple retrofits). Contrary to the default assumption that households are stable entities, households evolve even over short periods of time, sometimes substantially. Also, households may change their behavior because of the energy-efficiency upgrades they made; e.g., because thermal comfort is now easier to attain, or the perceived price of this comfort is lowered. The team also strongly suspects that behavioral effects can substantially amplify building and technology upgrade effects - i.e., higher savers also "doing extra things/being more conserving" in addition to making hardware investments. However this suspicion was difficult to confirm, given the relatively small number of households available for study. Further exploring the connection between realized savings and the interest in and expectations of homeowners in a given retrofit technology is warranted, because this research has shown that these factors are also impactful.

Future research could clarify these relationships and effects. Also, improved research designs and data collection could allow more confident generalization of these findings to larger populations of owners of retrofit homes and to households that are candidates for energy upgrades. If researchers had complete data, including consumption information, more extensive analyses could be conducted and more confident selection of extreme cases would be possible. Also, more detailed and nuanced analyses that consider weather effects could be undertaken. If researchers had direct access to program participants, with appropriate incentives for supplying information (which might use higher interval metering and occupancy/scheduling diaries), they would be able to explore in greater depth the actual role(s) of occupant behavior in amplifying and dampening the effects of technology upgrades. Finally, if researchers had access to the complete modeling data, including information about model architecture (now proprietary) and auditor inputs, they would be able to analyze with greater accuracy the sources of error in auditing and modeling that create a situation where savings projections are, at best, crude approximations of reality, particularly at the household level. 



\subsection{References}

Brazeau RH and MA Edwards. 2011. "A review of the sustainability of residential hot water infrastructure: public health, environmental impacts, and consumer drivers." Journal of Green Building 6:77-95.

Heschong Mahone Group, Inc. 2009. Engineering Review: Home Energy Solutions Program. Oakland, California.

Maréchal K and L Holzemer. 2011. “'Habitual practice’ and domestic energy consumption: identifying and describing potential 'grips' for change." In the Proceedings of the 2011 ECEEE Summer Study, 8:2021-2029.

Ross JP and A Meier. 2000. Whole-house measurements of standby power. LBNL-45967, Lawrence Berkeley National Laboratory, Livermore, California. Available at http://escholarship.org/uc/item/6382h54p.

Stern PC. 1992. "What psychology knows about energy conservation.” American Psychologist 47:12241232. 



\section{Appendix A}

Case Summaries 



\section{Appendix A}

\section{Case Summaries}

The 18 case studies involved in the research — Cases A through S—are briefly summarized below.

\section{A.1 Case A}

This household was flagged in the hierarchal model analysis as having saved far less gas than projected by the engineering estimates. The billing analysis similarly indicated a lower than estimated savings, although some savings were observed. The engineering estimate of a $60 \%$ reduction in household energy cost was likely overly ambitious. Savings of $10 \%$ were evident in the bill analysis.

This home is a newer home, built around 2000, with high ceilings and over 2,500 $\mathrm{ft}^{2}$ of living space. The three bedrooms and two-and-a-half baths were split between two levels. Both heat and hot water are fueled by natural gas. The upgrades included both duct sealing and air sealing of the home. There was an addition to the home that has a misalignment of the thermal and vapor barrier, which was rectified as part of the retrofit but not captured as an energy-saving measure. In addition, low-flow devices and a handful of compact fluorescent lights (CFLs) were installed as part of the audit process.

Lighting behavior seemed to be conservative, but comfort settings were not optimized for energy. The residents included two adults and two minors. An occupancy change that occurred after the analysis period did not appear to have had any effect on the results. Cost control and sustainability were the primary motivators for the upgrade.

\section{A.2 Case B}

At 3,600 $\mathrm{ft}^{2}$, this suburban home was the largest in the study. The home was built in the late 1980s and is occupied by two adult residents. Through the Energy Trust of Oregon (ETO) program, insulation was added to the attic and crawlspace. Air sealing and duct sealing were also performed. A highefficiency natural-gas furnace was installed along with a new refrigerator. These measures were collectively projected to save roughly $45 \%$ of household energy cost. Billing data showed that in the year after the upgrade period the costs were about $10 \%$ lower than the pre-retrofit period. This reflected roughly a $25 \%$ reduction in gas use and an increase of over $10 \%$ in electricity consumption. In addition to the upgrades through the ETO program some minor upgrades were undertaken that predated the study period.

The primary factor in the decision to pursue the upgrades was to reduce utility bills and the homeowner felt that the upgrades were very effective toward this end. The incentives provided by the program, along with manufacturer rebates and tax incentives, were listed as reasons contributing to the timing of the upgrades. Both residents operated businesses out of the home. 


\section{A.3 Case C}

This household outperformed savings projections substantially. The modern home was built in the early 2000s and was the only slab-on-grade structure in the study. The two adult residents of the 1,900- $\mathrm{ft}^{2}$ home share an interest in sustainability, which was a factor in pursuing the upgrades. However, the primary reason for pursuing the upgrade was concern about the reliability of the existing heating system. This was based on a catastrophic failure of a heating system in a contemporary home in the neighborhood.

The upgrades to the home were the addition of attic insulation, air and duct sealing, and replacement of a hydronic heat system with a high-efficiency ductless heat pump. Other changes to the home may have contributed to the higher than expected savings, notably the removal of a fireplace and installation of double-cell insulating shades on most windows.

The behaviors of the residents were interesting in a number of ways. They were largely conscientious about the role of behaviors on their stated sustainability objectives, but convenience, comfort, and aesthetics all played a role. Nearly all lights in the home were CFLs, but those that were not were halogens selected for ambient quality. Natural light was managed well and used to maximum effect and thermostat settings were fairly optimized.

\section{A.4 Case D}

This home was one of a small group that demonstrated substantially higher levels of savings than projected in the engineering estimates. Other upgrades made by the homeowner could have contributed to the savings but were not incentivized through the ETO program and thus not included in the engineering estimate. Occupancy changes also may have had some effect, but these effects may have offset one another to some degree. The incentivized measures were projected to save less than $5 \%$ of the annual household energy cost. Actual use reflected a savings in excess of $30 \%$.

The 1,700- $\mathrm{ft}^{2}$ home was built around 1980. As part of the ETO program, ceiling insulation was added to the attic and the ducts were sealed and insulated. As alluded to, extensive actions were taken outside of the program that contributed to the improved performance. In some cases there were no incentives available, in others the homeowners may have opted to perform the work themselves. The improvements that contributed to the reduced consumption included replacement of a metal door that was reported to have been hot/cold to the touch depending on the season and a number of windows. A ground barrier and under-floor insulation were added to the crawlspace. In addition, a gas-fueled domestic hot water (DHW) system was replaced with an electric water heater in 2009.

Residency patterns shifted significantly during the study period. In the pre-intervention period, the house was occupied by two adults fairly constantly. After the intervention period, an additional adult resided in the house year-round, while the other two residents traveled for months at a time. The consumption patterns of the adult who moved in are believed to be markedly different than the other two residents.

\section{A.5 Case E}

This 2,900- $\mathrm{ft}^{2}$ home was built around 1910. It has six bedrooms and three baths on three levels. The household consisted of two adults and two school age children. As part of ETO programs, a new furnace 
was installed and the envelope was improved through air sealing and insulation additions in the attic, rim joists, and knee walls. A new high-efficiency washer and a ductless heat pump were installed during the same period. While the latter is an efficient piece of equipment, it is not considered an energy-saving measure, because the portion of the house that it conditions was not previously temperature controlled. The homeowner reports usage of this system is infrequent.

The main reason for pursuing the upgrade was to control energy costs within such a large house. The house has many large, 100-year-old windows. The cold could be felt coming off of the windows, but upgrades were not pursued for both cost and aesthetic reasons.

Billing data indicated that there was a marked increase in energy consumption after the retrofit activity. However, there was some concern and confusion around this case because the homeowners reported having taken up residence only a few months prior to the commencement of the upgrades. As such, it is unclear whether the change in consumption reflects consumption of the same household in two separate domiciles or two different households occupying the home in question.

\section{A.6 Case $F$}

This house underwent extensive upgrades and achieved substantial savings, but not to the level of the projections. Built in the 1940s, the bungalow has about $800 \mathrm{ft}^{2}$ of living space on a single level. The upgrades included insulating the floor, air sealing, duct sealing and insulating, and installing a highefficiency electric water heater. The engineering estimate for savings from these measures was projected to be $60 \%$ of household energy expenses. Billing data indicated a substantial savings of over $20 \%$.

This household was the lone participant in the study that had participated in the Clean Energy Works program, which provides on-bill financing of energy-efficiency upgrades. The respondent felt that during the heating season the energy savings were sufficient to offset the financing charge of the upgrades. The cost leveling of the financing likely improves the perception of return; the payback based on savings and payments through the first year is on the order of 20 years.

The one resident of this home is retired and has made extensive efforts to become knowledgeable about household energy use and the financial impacts on the ability to "age in place" in the home. This knowledge and desire is manifested in the practice of a number of energy-conserving behaviors. Both lighting and thermal control was fastidious. In fact, this was one of the only residents of households in the study who claimed to turn off the heat when leaving the house.

\section{A.7 Case G}

This case was an uncommon instance in which there was an apparent marked increase in household energy costs in the period after the retrofit activities. This four-bedroom, two-bath house included two floors and an unfinished basement and was built in the 1920s. Both heating and DHW are fueled by natural gas. The home energy upgrades included some window upgrades, an Energy Star refrigerator, and the addition of insulation in the walls, attic, and knee walls. Low-flow faucet aerators and showerheads were also installed during the review process. The engineering estimate of the savings from these measures was approximately $60 \%$ of household energy expense for the 12-month period preceding the upgrade. Billing data showed instead an increase of over $50 \%$ in the 12-month period after the upgrade. 
The lone resident of the household reports being home most of the time since retiring shortly prior to the study period. The primary reason for pursuing the upgrades was to improve the comfort of the home, and homeowner felt that this had succeeded. Generally speaking, there were many conserving behaviors (programmable thermostat use, storm window use, light conservation) and non-incentivized changes (gas fireplace insert, insulating blinds) present that are frequently found in households where savings had been achieved. One possible explanation for the increased consumption could be the date of the retirement.

\section{A.8 Case H}

This case had one of the most surprising results based on billing analysis. While the engineering estimates projected a $30 \%$ decrease in energy consumption, actual results indicated a nearly $90 \%$ increase. Through the interview, it was determined that the cause of this discrepancy was an error in the data, indicating that there was more than 12 months of consumption data despite the homeowners taking occupancy less than 2 months prior to beginning upgrades. There were also issues with minor DHW measures being assigned therm savings despite the hot water service being provided by an electric hot water heater. As such, the researchers could not accurately assess the effect of the upgrades undertaken. Even so, this case was of interest in a number of areas.

The only reason cited by the homeowner for pursuing the upgrades was to improve the comfort of the home. Toward this end, air sealing was performed and wall and floor insulation was added. A highefficiency clothes washer and low-flow faucet aerators were installed. While there was no basis for the homeowner to assess cost savings there was a very low level of satisfaction with the upgrades with respect to improving home comfort. This 1,600- $\mathrm{ft}^{2}$ home was built around 1910 and was considered to be extremely drafty and cold when the homeowners first moved in. While drafts are no longer considered to be the main problem, cold radiating from the large windows is the main issue. These single-paned wood windows have no storm windows. The windows were recommended for replacement through the ETO program, but were considered to be cost prohibitive.

\section{A.9 Case J}

This household achieved one of the highest levels of savings found in the study. The energy consumption for the 12-month period after the upgrade activity showed a $30 \%$ reduction compared to the preceding period. The engineering estimates of the savings were audacious, in excess of $80 \%$, placing this clearly in the realm of deep energy retrofits. These upgrades included air sealing, insulation of the walls and ceiling, and extensive appliance replacement. During the upgrade period, a new furnace, hot water heater, clothes washer, and refrigerator were installed along with low-flow faucet aerators and showerhead.

This 2,000- $\mathrm{ft}^{2}$ home was built in the 1910s and has two bedrooms and one bath. The finished area is only $1,350 \mathrm{ft}^{2}$. This discrepancy may have contributed to the high savings estimates. The two adult residents were joined by a minor in the post-intervention period. The upgrades were pursued to improve the comfort of the home and reduce utility bills. The residents are highly pleased with the comfort improvement and unsure of the impact on utility bills. The residents were highly motivated and interested in energy efficiency. Many conservation behaviors and additional measures outside of the ETO program were undertaken, such as re-plumbing hot water through interior rather than exterior walls. 


\section{A.10 Case $\mathrm{K}$}

This household achieved savings roughly double the projected 20\%. All savings were from electricity, because both heat and DHW were provided by electricity. This was the only all electric home in the study, as well as the only one to have had a concurrent photovoltaic installation. The projected generation from the photovoltaic system is included in the savings projections. In addition to the photovoltaic system, a ductless heat pump system was installed and commissioned, replacing a gas system. Insulation was added to the attic and air sealing was performed throughout the house. In addition to these incentivized measures, a number of windows were replaced and some minor DHW measures were installed.

It was somewhat surprising that the energy consumption was as close to the projection as it proved to be. Fuel switching can cause some level of inaccuracy, because it assumes the savings to be in the fuel of the system installed. In this case, a sharp drop in gas use would have been offset by an increase in electrical use from the heat pump. This may have been offset by higher than anticipated generation from the photovoltaic system, because decreases were seen in consumption of both gas and electricity.

The house was built in the late 1930s and has about 2,600 $\mathrm{ft}^{2}$ of living space. Two adults and two children live in the house. The children seemed to have played a key role in the upgrades, because the effort began with a home energy kit being brought home from school. In addition the upgrades were viewed as an expression of values - "the right thing to do." Reducing energy costs and increasing the value of the home were also cited as factors.

\section{A.11 Case L}

This suburban home was built in the early 1970s. The home has about 2,300 $\mathrm{ft}^{2}$ of living space, and both heat and DHW are fueled by natural gas. The two residents include the homeowner and a renter, both of whom work full-time outside the home.

The household outperformed its savings projections by a substantial amount, achieving an over $30 \%$ cost reduction against a projection of less than 10\%. Measures included the addition of ceiling insulation, air sealing, and window upgrades throughout the house. A high-efficiency clothes washer was also added. Controlling costs and protecting the environment were cited as the primary reason for pursuing the envelope upgrades, although the appliance was a replacement of an obsolete unit. There was no apparent reason for the much better than projected performance. One possibility may have been reduced use of the onsite swimming pool, with its considerable heating and filtration requirements.

\section{A.12 Case M}

This 2,000-ft home was built in the 1960s and has been extensively upgraded over the past 10 years. The upgrades incentivized as energy conservation measures by the ETO program were air sealing, additional attic insulation, and installation of insulation in the crawlspace. Most of the home's windows were replaced through the ETO program, with a notable exception (discussed below). These measures were projected to reduce household energy cost in excess of 50\%. However, both the statistical model and bill analysis indicated much lower savings, on the order of $10 \%$. 
The factor that most prominently affected the performance of the home during the study period was changes in occupancy shortly after the upgrades were completed. An elderly parent moved into the house adding not only the marginal consumption of an added resident, but drastically changing the heating and cooling requirements. This move coincided with one of the residents stopping work outside of the home. While the respondent stated that prior to the parent moving in, a programmable thermostat was used, after the move, the house was held at a constant 80 degrees year-round. However, lighting choices and behaviors skewed toward conservation.

Increasing the value of the home was the primary motivation behind the upgrades and the incentives served as a strong factor in determining what changes were made. While most of the windows in the home were upgraded, a large bay window was not. It was stated that the incentives would not have covered its replacement. This window posed comfort issues and had stains from where condensation had run down to the wall below. The homeowner indicated a high level of satisfaction with the upgrades and believed they have achieved the objective of increasing home value.

\section{A.13 Case N}

This suburban 2,300- $\mathrm{ft}^{2}$ house was built in the late 1980s and used natural gas for thermal utilities. The upgrades through the ETO program were extensive, addressing envelope, appliances, and DHW. The envelope was addressed through air and duct sealing, additional ceiling insulation, and the addition of floor insulation to a previously un-insulated crawlspace. There were also water-focused measures, including a new clothes washer and low-flow adaptors for faucets and showers. These measures contributed to substantial energy savings. The billing data indicated a more than $40 \%$ reduction in household energy costs, slightly above projections.

This household was highly interesting in a number of aspects. It was a large home for only two adult residents, and there were strong indications that their behaviors may have been divergent. The interviewee seemed largely aware of many energy concerns, claiming to have never touched the thermostat, which was not only programmable, but highly customized, with large swings to maintain comfort during occupied times while maintaining minimal use when the residents were at work. In fact, the respondent's estimates of set points for both heating and cooling were off by about 10 degrees. There were no active conservation behaviors indicated during the interview. Something of interest was that the individual responsible for the thermostat settings was reported to be less conscientious about lighting use. In discussing the motivation for pursuing the upgrade, the reasons were entirely financial.

\section{A.14 Case P}

This 2,500- $\mathrm{ft}^{2}$ home built in the 1950s has two retired residents. Both residents retired prior to the study period and maintain varied schedules. This household substantially outperformed savings projections. A cost reduction of over $30 \%$ was shown for the year after the upgrades in comparison to the 12 -month period preceding them. The engineering estimate was below $10 \%$ for measures that included air sealing, ceiling insulation, and wall insulation. Improving comfort and reducing costs were cited as the primary factors in pursuing upgrades.

Hot water is heated by natural gas. There are two heating systems in the home, which is likely the cause of the discrepancy between the projections and results. The main part of the house was heated by a natural-gas forced-air furnace. However there was an addition consisting of a large room and hallway, 
both of which were heated primarily by wall-mounted electric convection heaters. The building envelope upgrades yield savings estimates only for the primary heating fuel, in this case gas. In addition to those savings, there should be reduced consumption of electricity to heat the addition as well as air conditioning in the summer. The homeowner reported considerable air-conditioning use.

\section{A.15 Case Q}

This household was flagged in the hierarchal model analysis as having saved far less gas than projected by the engineering estimates. The billing analysis similarly indicated lower than estimated savings, but savings were indicated. There was an engineering estimate of a $20 \%$ reduction in household energy cost, while savings of $10 \%$ were evident in the bill analysis. The main measure leading to the saving projection was air and duct sealing. Other minor measures such as installation of compact fluorescent bulbs were also noted.

One of the larger homes in the study, this residence has over $3,000 \mathrm{ft}^{2}$ in living space on four offset levels. The living area, set below the kitchen and dining spaces, notably had a set of very large singlepane windows totaling at least $100 \mathrm{ft}^{2}$. The residents reported large temperature differences in the areas adjacent to these windows and altered behavior as a result. The thermal envelope upgrade of air sealing had noticeable effects, but not in the living area where most of the time was spent. Both heating and DHW were fueled by natural gas. The house was built in the early 1990 s.

\section{A.16 Case $R$}

This recent suburban home was built in the early 1970s and underwent comprehensive envelope upgrades as part of the ETO program. These included the addition of ceiling and floor insulation as well as air and duct sealing. These changes resulted in the household slightly exceeding its savings projections of about $40 \%$ of household energy cost.

Two occupants resided in the household throughout the study period. Two additional adult residents were in the home during the pre-intervention period only. The household reported very strong conservation behaviors, particularly around thermal management, using a thermostat program, and turning the system off when leaving the home. Lighting was also managed conscientiously. The motivations for pursuing the upgrades were cost control, sustainability, and a desire to better understand the energy measures as part of a professional association with the building field.

\section{A.17 Case S}

This urban home was built in the first decade of the 1900s. The household had been identified based on a substantial increase in energy costs after the upgrade. Through the interview process, it became clear that this increase resulted primarily from the switch from oil heat for which no consumption data were available. This system was replaced with a ductless heat pump. The reasons for pursuing this change were cost control and reduction of the carbon footprint. The success against these criteria was difficult to measure, because the filling of the oil tank is as needed rather than monthly and carbon is largely amorphous. The household was enrolled in a carbon offset program for electric consumption. The level of satisfaction was high overall, particularly with the avoidance of large, lump sum oil payments. 
In addition to the heating system change, floor, ceiling, and wall insulation was added throughout the home. This included parts of the basement, which was, at times, heated. This made it unclear as to what should be considered the conditioned space of the home. The occupancy changed during the study period, with a minor part-time resident leaving the household during the post-upgrade period.

Conservation behaviors were practiced in a number of areas, with extensive use of natural lighting and electronics being unplugged when not in use. 


\section{Appendix B}

\section{Energy Trust Introductory Letter}





\section{Appendix B}

\section{Energy Trust Introductory Letter}

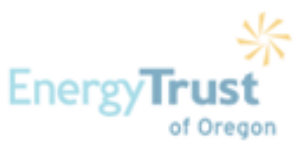

\section{Portland State}

Dear

(homeowner name)

We would like your help! We would like to invite you to participate in a study of energy use in homes that have taken part in Energy Trust of Oregon's Home Performance with Energy Star program. The information from the study will provide us with invaluable feedback that will be used to enhance our residential programs, such as the one you participated in. Energy Trust will be performing this study in collaboration with a research team at Portland State University.

Participation in the study will involve a phone interview about changes made to your home, a survey of household energy use activities and habits, and a possible on-site follow-up interview to assess the energy efficiency upgrades you have made to your home.

A member of the research team from Portland State University will contact you by phone within a week to ask a few preliminary questions and schedule an interview if you choose to participate in the study. If you do not wish be contacted at all, you may notify me by telephone or email.

Any information you provide us during the course of the study will be keptstrictly confidential. No information about you will be shared or made public in any way, as no personally identifiable information collected during the course of the study will be kept. Your participation is voluntary and your willingness to complete this survey and/or follow-up interview will not affect your eligibility for future programs with the Energy Trust.

Thank you in advance and I hope that you will be willing to participate in this study. If you have any questions of concerns, please feel free to send me an email or give me a call. You can find my contact information below.

Sincerely,

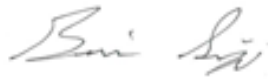

Brien Sipe

Evaluation Project Manager

Energy Trust of Oregon

Tel: $\quad 503.459 .4069$

Email: brien.sipe@energytrust.org

If you have concerns or problems about your participation in this study or your rights as a research subject, please contact the Portland State University Human Subjects Research Review Committee, Office of Research and Sponsored Projects, 600 Unitus Bldg., Portland State University, (503) 725-4288/ 1-877-480-4400. 

Appendix C

Gift Card Documents 



\section{Appendix C}

\section{Gift Card Documents}

\section{PSU Energy Savings Study}

If you wish to receive a gift card as an acknowledgement of your time and effort in participating in this study, please complete the fields below and choose your card from the options below. We will mail cards within two weeks of the completion of interview and receipt of this form.

Mailing Address:

Participant Signature:

Participant Name (Please print): Date:

You will receive a $\$ 25$ gift card to one of the following shops or restaur ants. Please indicate your preference for the cards by placing an " $x$ " in the box that corresponds with your choice. If you would prefer not to receive a gift card or participate in the study, please mark the appropriate box.

Fred Meyer

New Seasons

Target

Burgerville

Declined Card

Declined Interview

\section{Office Use Only}

Household ID:

Card \#:

Particlpant vendor *

Check or DD amount \$

Date malled:

$-1$ I

Initlals:

Banner Involce * 


\section{Portland State}

Name

Address

City, OR ZIPCD

March 8, 2012

Dear Name,

If you are willing to participate in this study, we would like to offer you a $\$ 25$ gift card in appreciation for your time and effort.

To receive your gift card, all you need to do is complete the top part of the form included, return it using the pre-paid envelope and complete an interview with one of our researchers. Please make sure to select which card you would like to receive and sign the form in order to allow for processing. Your gift card should arrive within 2 weeks of completing the interview.

If you would like schedule an interview now, rather than waiting for our call, please contact me at lancastr@pdx.edu or (503) 725-8981.

Best regards,

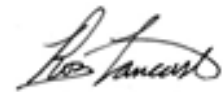

Ross Lancaster

Research Engineer

Center for Urban Studies

Portland State University

503.725 .8981

lancastr@pdx.edu 



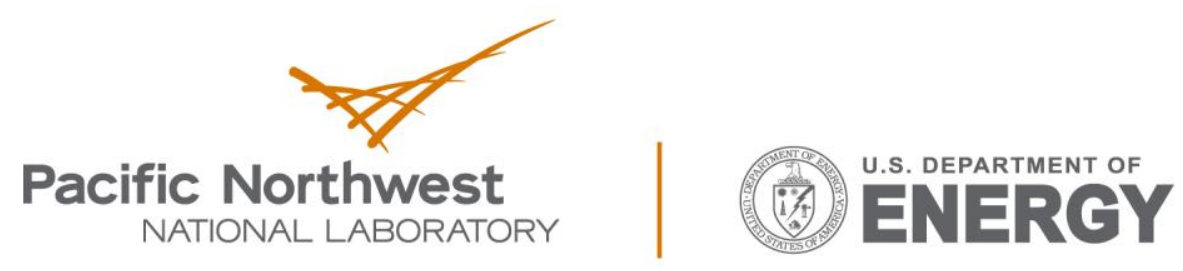

Proudly Operated by Battelle Since 1965

902 Battelle Boulevard

P.O. Box 999

Richland, WA 99352

1-888-375-PNNL (7665)

www.pnnl.gov 